REVIEW ARTICLE

\title{
Pain Perception and Response: Central Nervous System Mechanisms
}

\author{
Arthur J. Hudson
}

\begin{abstract}
Although several decades of studies have detailed peripheral and ascending nociceptive pathways to the thalamus and cerebral cortex, pain is a symptom that has remained difficult to characterize anatomically and physiologically. Positron emission tomography (PET) and functional magnetic imaging (fMRI) have recently demonstrated a number of cerebral and brain stem loci responding to cutaneous noxious stimuli. However, intersubject variability, both in the frequency and increased or decreased intensity of the responses, has caused uncertainty as to their significance. Nevertheless, the large number of available imaging studies have shown that many areas with recognized functions are frequently affected by painful stimuli. With this evidence and recent developments in tracing central nervous system connections between areas responding to noxious stimuli, it is possible to identify nociceptive pathways that are within, or contribute to, afferent spinothalamo-cortical sensory and efferent skeletomotor and autonomic motor systems. In this study it is proposed that cortical and nuclear mechanisms for pain perception and response are hierarchically arranged with the prefrontal cortex at its highest level. Nevertheless, all components make particular contributions without which certain nociceptive failures can occur, as in pathological pain arising in some cases of nervous system injury.
\end{abstract}

RÉSUMÉ: La perception et la réponse à la douleur: mécanismes nerveux centraux. Bien que des études effectuées au cours des dernières décennies aient décrit de façon détaillée les voies nociceptives périphériques et ascendantes vers le thalamus et le cortex cérébral, la douleur est demeurée un symptôme difficile à caractériser au point de vue anatomique et physiologique. La tomographie par l'émission de positons et l'imagerie par résonance magnétique fonctionnelle ont démontré récemment l'existence d'un certain nombre de sites qui répondent à des stimuli cutanés désagréables. Cependant, la variabilité entre les sujets, tant quant à la fréquence qu'à l'augmentation ou la diminution de l'intensité de la réponse, a causé de l'incertitude sur leur signification. Toutefois, les nombreuses études d'imagerie disponibles ont montré que plusieurs zones qui ont des fonctions bien reconnues sont fréquemment touchées par les stimuli douloureux. Avec ces données et les développements récents dans la cartographie des connections entre les zones répondant aux stimuli désagréables dans le système nerveux central, il est possible d'identifier les voies nociceptives qui sont à l'intérieur ou qui contribuent au système afférent sensitif spino-thalamocortical et aux systèmes efférents moteurs squelettique et autonome. Dans cette étude, l'hypothèse proposée est que les mécanismes corticaux et nucléaires de la perception de la douleur et de la réponse à la douleur sont structurés de façon hiérarchique, le cortex préfrontal étant placé au plus haut niveau de la hiérarchie. Cependant, toutes les composantes fournissent une contribution particulière sans laquelle certaines défaillances nociceptives peuvent survenir comme c'est le cas dans la douleur pathologique observée dans certains cas de lésion du système nerveux.

Can. J. Neurol. Sci. 2000;27: 2-16

Since Melzack and Wall ${ }^{1}$ proposed a gate control model for pain perception and response 35 years ago, there have been significant advances toward understanding the central nervous system mechanisms subserving pain. However, there is still no general agreement as to its nature nor the manner in which pain is processed within the nervous system. ${ }^{2}$ Speculation as to a "pain centre" has been generally criticized because of the many cortical and subcortical structures that are involved and attempts to elicit pain by electrical stimulation of the human cortex and thalamus has only rarely been successful. ${ }^{1,3,4}$ Also, studies of post-stroke pain or attempts at central nociceptive deafferentation have not shown localization to a specific part of the nervous system except that damage to the spino-thalamocortical pathway is apparently necessary. ${ }^{5-7}$ Nevertheless, patients experiencing pain show sufficiently reproducible

\footnotetext{
From the Department of Clinical Neurological Sciences, University of Western Ontario, London, Ontario, Canada

RECEIVED JANUARY 12, 1999. ACCEPTED IN FINAL FORM AUGUST 24, 1999 Reprint requests to: Arthur J. Hudson, Department of Clinical Neurological Sciences, London Health Sciences Centre, 339 Windermere Rd., London, Ontario, N6A 5A5
} 


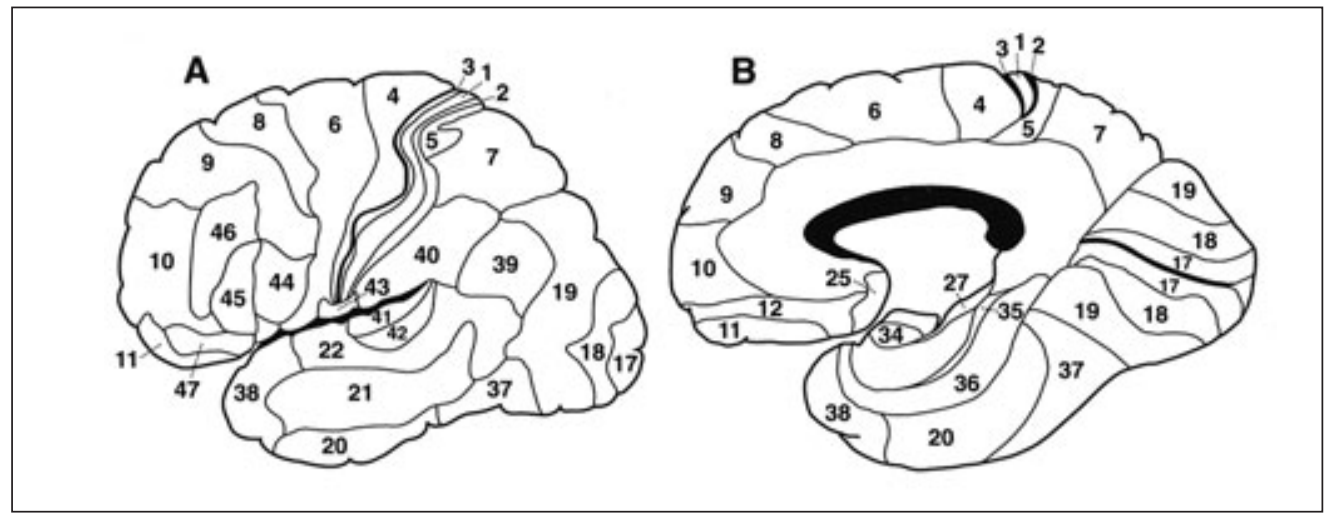

Figure 1. Human cerebral cortex showing cerebral lateral (A) and medial (B) cytoarchitectural areas as described by Brodmann. ${ }^{88}$ The excluded areas on the medial surface are illustrated in Figure 3 (cingulate cortex).

responses when examined by either electrophysiological methods or regional blood flow (rCBF) measurements, using positron emission tomography (PET) and functional magnetic imaging (fMRI), to suggest a nociceptive system consisting of afferent and efferent components.

The ascending nociceptive pathways in the spinal cord and brain stem to the thalamus have been extensively explored since the latter part of the nineteenth century but only very recently have many thalamic and other cerebral connections been identified. ${ }^{8,9}$ Lateral and medial thalamic regions that are involved in processing sensory-discriminative and motivationalaffective aspects of pain, respectively, are now recognized through electrophysiological studies. ${ }^{10,11,12}$ Brodmann's area 24 of the anterior cingulate cortex, where a nociceptive area (24c) receiving medial thalamic projections has been identified (see Figure 3), was first recognized as producing complex cardiovascular, respiratory and pupillary autonomic responses and altered emotional expression when electrically stimulated in the monkey by Smith. ${ }^{13}$ Shortly afterward, Ward ${ }^{14}$ reported that anterior cingulate ablation in primates produced a state of social indifference and loss of fear (tameness). Foltz and White, ${ }^{15}$ noting similar behaviour in the human following frontal lobotomy, postulated "that transection of the cingulum might be of benefit in those clinical cases of intractable pain in which marked emotional factors appeared to contribute to the intolerable situation". When undertaken, they found that the noxious quality of chronic pain was alleviated although pain was still present and, therefore, it remained uncertain whether the emotional reaction to, rather than the pain itself, was relieved. Frontal lobotomy (or leucotomy) is a procedure that often interrupted prefrontal connections between the thalamus and anterior cingulate cortex and similar effective relief of pain has been achieved with lesions involving the midline parafascicular nucleus and intralaminar nuclei of the thalamus. ${ }^{16,17}$ Indeed, Vogt et al. ${ }^{18}$ more recently described thalamic afferents from the midline and intralaminar nuclei to the anterior cingulate cortex and suggested that their input, and possibly those from regions such as the amygdala and insula, might be contributors to the noxious aspects of pain.
With the arrival of PET it became possible to explore, by indirect means, cerebral changes occurring in response to painful injury. Jones et al.$^{19}$ found that cutaneously applied painful heat produced increased blood flow in area 24 of the contralateral anterior cingulate cortex, the thalamus and lenticular nucleus (Figures 2 and 3). In contrast, activity was not observed in either the primary ( $\mathrm{S} 1)$ or secondary (S2) cortical somatosensory areas, although increased activity has since been described by others in both. This suggested to the authors that pain was a predominantly emotional response to potentially damaging stimuli. Jones et al. ${ }^{20}$ also found high levels of opioid receptor binding in the projections of the medial thalamic pain system to both the anterior cingulate region and the prefrontal cortex.

Since the report of Jones et al. ${ }^{19}$ PET has been used to show that many areas of brain respond to nociceptive stimuli but, more recently, brain imaging has been improved with the introduction of fMRI (Table 1). ${ }^{2,4,12,19,21-33}$ PET and fMRI monitor increases or decreases in $\mathrm{rCBF}$ or blood oxygen utilization by different methods. The PET studies employ a radiotracer $\left(\mathrm{H}_{2}{ }^{15} \mathrm{O}\right)$ in the determination of changes in blood flow whereas fMRI measures changes in magnetic fields as a function of blood flow and blood oxygen saturation. ${ }^{34,35}$ PET has been highly useful in locating areas of brain responding to noxious stimuli but, in comparison with fMRI, spatial resolution (measured in $\mathrm{mm}$ ) is less precise, scan times are longer and results depend upon averaged group data ${ }^{35}$ Because of its greater precision and speed and usefulness in studying individual subjects, most studies of nociception using fMRI have tended to focus upon spatial and temporal resolution of pain-related activity in particular regions, such as the anterior cingulate cortex or thalamus, that have been previously identified on PET scans. ${ }^{35-42}$ Comparisons of different individuals have shown that fMRI responses to the same stimulus, within a particular area, is variable in location and it can also differ in extent over time depending on pain duration and intensity. ${ }^{39,42}$ Nevertheless, PET provides reproducible data that are comparable to fMRI on the areas of brain responding to painful stimuli. Whereas increased $\mathrm{rCBF}$ can be correlated with vasodilatation and increased oxygen utilization, attributable to increased neuronal activity, the significance of a decreased 
Case Studies (References)

\begin{tabular}{llllllllllllllllll}
\hline 1 & 2 & 3 & 4 & 5 & 6 & 7 & 8 & 9 & 10 & 11 & 12 & 13 & 14 & 15 & 16 & 17 & 18 \\
$\left(21^{\ddagger}\right.$ & $22^{\ddagger}$ & $23^{\ddagger}$ & $24^{\ddagger}$ & $31^{\ddagger}$ & 19 & 25 & 2 & 26 & $12^{*}$ & $12^{*}$ & 27 & 28 & 29 & 30 & 4 & 32 & $33)$
\end{tabular}

Thalamus

$\uparrow_{\mathrm{B}}-\quad-\quad-\quad-\uparrow_{\mathrm{C}} \uparrow_{\mathrm{B}}-\uparrow_{\mathrm{C}}-\uparrow_{\mathrm{C}}-\uparrow_{\mathrm{B}}-\uparrow_{\mathrm{C}}-\uparrow_{\mathrm{B}} \uparrow_{\mathrm{C}} \uparrow_{\mathrm{I}}$

Anterior cingulate

- area 24

- $\operatorname{area} 25$

- area 32

Posterior cingulate

- $\operatorname{areas} 23,29,30,31 \downarrow_{\mathrm{R}} \quad-\quad \downarrow_{\mathrm{B}}$

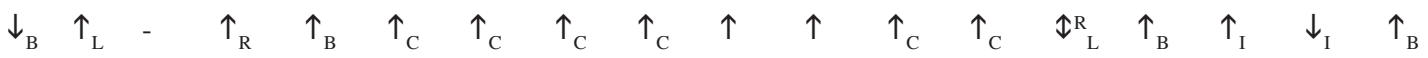
$\uparrow_{\mathrm{L}}-\quad-\uparrow_{\mathrm{C}}$

Somatosensory

- S1 areas 3, 1, 2

- S2

$\begin{array}{lllll}- & \uparrow_{\mathrm{L}} & \uparrow_{\mathrm{B}} & \uparrow_{\mathrm{R}} & \uparrow_{\mathrm{B}}\end{array}$

Parietal

- areas 7,39, 40

Insula

Prefrontal

- area 8

- area 9

- area 10

- area 44

- area 45

- area 46

- area 47

Basal ganglia ${ }^{\dagger}$

Supplementary motor

Premotor area 6

$$
\text { - } \quad \uparrow_{\mathrm{B}}
$$$$
\uparrow_{I} \downarrow_{I}
$$$$
\downarrow_{\text {B }}
$$$$
\uparrow_{\mathrm{B}} \quad \downarrow_{\mathrm{C}}^{\mathrm{I}} \quad \downarrow_{\mathrm{I}} \quad \uparrow_{\mathrm{C}}
$$

Primary motor area 4

Periaqueductal gray

and brain stem

Cerebellum

Hypothalamus

Occipital

- areas 17, 18, 19

$\begin{array}{lllll}\downarrow_{\mathrm{L}} & - & \downarrow_{\mathrm{B}} & \downarrow_{\mathrm{B}} & \uparrow_{\mathrm{B}} \\ - & - & \uparrow_{\mathrm{B}} & \uparrow_{\mathrm{B}} & -\end{array}$

$$
\begin{array}{lll}
\uparrow_{\mathrm{C}} & \uparrow_{\mathrm{C}} & \uparrow_{\mathrm{C}} \\
\uparrow_{\mathrm{B}} & \uparrow_{\mathrm{C}} & \uparrow_{\mathrm{C}}
\end{array}
$$$$
\downarrow_{\mathrm{C}} \quad-\quad \downarrow_{\mathrm{B}} \quad \uparrow_{\mathrm{B}}
$$

Temporal lobe

$$
\begin{aligned}
& \text { - superior - area } 22 \text { - } \\
& \text { - middle - area } 21 \\
& \text { - inferior - areas 20,37 - } \\
& \text { - polar - area } 38
\end{aligned}
$$

$\begin{array}{llll}- & - & \downarrow_{R} & - \\ - & - & \downarrow_{R} & \uparrow_{R} \\ \uparrow_{B} & \uparrow_{L} & \downarrow_{R} & \downarrow_{B} \\ \uparrow_{B} & - & \uparrow_{B} & \uparrow_{B} \\ - & - & - & \uparrow_{B}\end{array}$

Hippocamp. formation -

Amygdala

Fusiform gyrus

- areas 28, 35

rCBF symbols: $\uparrow=$ increased; $\downarrow=$ decreased; $\mathfrak{\downarrow}=$ increased and decreased; dash $(-)=$ no response. The side of response is shown in superscript and subscript symbols: $\mathrm{C}=$ contralateral; $\mathrm{I}=$ ipsilateral; $\mathrm{B}=$ bilateral; $\mathrm{R}=$ right; $\mathrm{L}=$ Left.

\$ The first 5 columns were studies on (1) angina pectoris, (2) intestinal pain, (3) oesophageal pain, (4) cluster headache, (5) migraine.

Lateralization of pain stimulus in some studies varied. Case 17 was diagnosed lateral medullary syndrome.

* Two studies were described in same paper: noxious stimuli (control cases) and atypical facial pain.

$\dagger$ Described as corpus striatum, lentiform nucleus or putamen. 
response remains unclear. It may reflect diminution of ongoing neuronal processes as an outcome of increased neuronal activity elsewhere. ${ }^{43}$ Also, responses are usually lateralized and most often contralateral to a noxious stimulus but the side can be unpredictable.

As stated above, the normal nociceptive pathways, as they extend from the periphery to the thalamus, have been familiar for decades and only recently, have nociceptive projections to other areas of the brain responding to painful stimuli, been recognized. ${ }^{8,19}$ Many of the recent advances can be credited through detailed anatomical tracings and ongoing physiological studies of pathways in the spinal cord and between cortical regions and nuclei. With the introduction of PET and fMRI, many of these regions of brain that were hitherto unappreciated in their significance to pain, were seen to participate in the processing of nociceptive information. The prefrontal cortex, especially in its connections and functions, is now better understood and shows a number of areas responding to painful stimuli, which suggests that it probably has a prominent role in pain awareness and response. ${ }^{44-47}$ The objective of this review is to attempt to integrate these multiple areas of response into a system of afferent and efferent pathways to enable better understanding of the significance of pain.

\section{DORSAL HORN AND TRIGEMINAL NUCLEUS}

Pain is normally experienced when peripheral branches of unmyelinated (group C) and small diameter $\mathrm{A} \delta$ myelinated axons are activated by noxious chemical, mechanical, electrical or thermal stimuli. Activation produces an electrical discharge that is initiated by nociceptive receptor cation channels and conducted along axons entering the medulla oblongata to the nucleus of the trigeminal spinal tract or, in the case of those entering the spinal cord, to the dorsal horn where processing of nociceptive information begins. ${ }^{48}$ In the trigeminal nucleus and dorsal horn, information on pain is extensively processed, both locally and by descending fibres from higher levels of the nervous system, before contact is made with the cells of origin of the trigeminothalamic and spinothalamic tracts.

Whereas several different neurotransmitters are released in the dorsal horn (and corresponding trigeminal nucleus) during noxious stimulation, pain response is believed to be mediated locally by the release of L-glutamate, the principal transmitter signalling pain at all intensities, and substance $P .49,50$ Substance $\mathrm{P}$ does not mediate acute pain but modulates sensitivity to pain and is essential for the "windup" response - a NMDA ( $N$-methyl-Daspartate) mediated augmentation of the response of the dorsal horn nociceptive neurons to a constant repeated stimulus. ${ }^{51,52}$ Substance P and another tachykinin, neurokinin A (and possibly other sensory neuropeptides), can also be released from peripheral sensory nerve terminals in skin and various tissues at higher stimulus intensities producing "neurogenic inflammation" and a state of increased moderate to intense pain. ${ }^{50,53}$ De Felipe et al. $^{52}$ have proposed that substance $\mathrm{P}$ also generates stressinduced analgesia by activating central inhibitory pathways from the brain stem, a process that is pharmacologically distinct from the opiate-mediated pathway (see below).

Descending spinal cord pathways also significantly influence nociception. Tract-tracing studies have shown that fibres from the precentral motor cortex and somatosensory cortex (areas 1,2, 3 , and 5) terminate in the posterior parts of the dorsal horn, although most extensively in laminae VI and VII, where they may have a direct influence on nociceptive responses (Figure 1). ${ }^{54-57}$ Descending fibres, having an indirect influence on nociceptive thresholds, have been traced from the prefrontal cortex, hypothalamus and amygdala to the periaqueductal gray matter and other brain stem nuclei that project to the trigeminal nucleus and dorsal horn.

Descending fibres can have important inhibitory influences on medullary and spinal nociceptive neurons and are divisible into those which act on either opioid or non-opioid receptors. ${ }^{58}$ Activation of neurons in the periaqueductal gray produces direct antinociception that is $\mu$-opioid receptor-mediated in the dorsal horn. ${ }^{59}$ This may be due to a direct action on either primary afferents or by way of local circuit neurons in the substantia gelatinosa. The periaqueductal gray also projects to the nucleus raphe magnus in the medullary reticular formation where nonopioid effects on the dorsal horn via serotonergic fibres are relayed to the substantia gelatinosa (lamina II). ${ }^{60-63}$ Electrical stimulation of either the periaqueductal gray or nucleus raphe magnus produces profound analgesia. ${ }^{63,64}$ Noradrenergic fibres, in a descending pathway from the locus coeruleus, end in the dorsal horn where they also have an inhibitory role on nociceptive responses ${ }^{65}$ Hitoto et al ${ }^{66}$ suggest that noradrenergic analgesia is produced by stimulation of $A \delta$ afferent fibres which activate descending locus coeruleus neurons causing an increase in noradrenaline level in the dorsal horn. Still other small molecule and peptide neurotransmitters are involved in modulating nociception but their roles have generally been less clearly defined. ${ }^{67-69}$

Ascending pathways carrying nociceptive information are: (i) the ventral trigeminothalamic tract from the nucleus of the spinal trigeminal tract in the medulla and (ii) the spinothalamic, spinoreticular and spinomesencephalic tracts from the dorsal horn. These terminate in various parts of the brain stem reticular formation and, ultimately, thalamus. Willis, ${ }^{49}$ has suggested that the sensory-discriminative aspects of pain proceed principally by way of the spinothalamic pathway whereas motivationalaffective influence requires all three ascending tracts. Most trigeminothalamic and spinothalamic tract fibres terminate in the ventral posterior nucleus of the thalamus whereas some, specifically involved in experiencing pain, end in the intralaminar and, to a lesser extent, in the midline nuclear region of the thalamus and have much larger receptive fields. ${ }^{9}$ Comparisons of PET responses in the thalamus following cranial and spinal nociceptive stimulation, as shown in the Table, are similar. ${ }^{31,70,71}$ A generally unfamiliar pathway is the spinohypothalamic tract that arises in the dorsal horn and carries nociceptive information directly to the limbic system. ${ }^{72}$ Similar to the motivational-affective system, it may be directly involved in emotional and autonomic regulation and might also have nociceptive reflex potential.

\section{Thalamus}

The thalamus is the major sensory relay station where sensory information is sorted for delivery to the cortex and subcortical nuclei. As noted above, nociceptive pathways upon entering the 


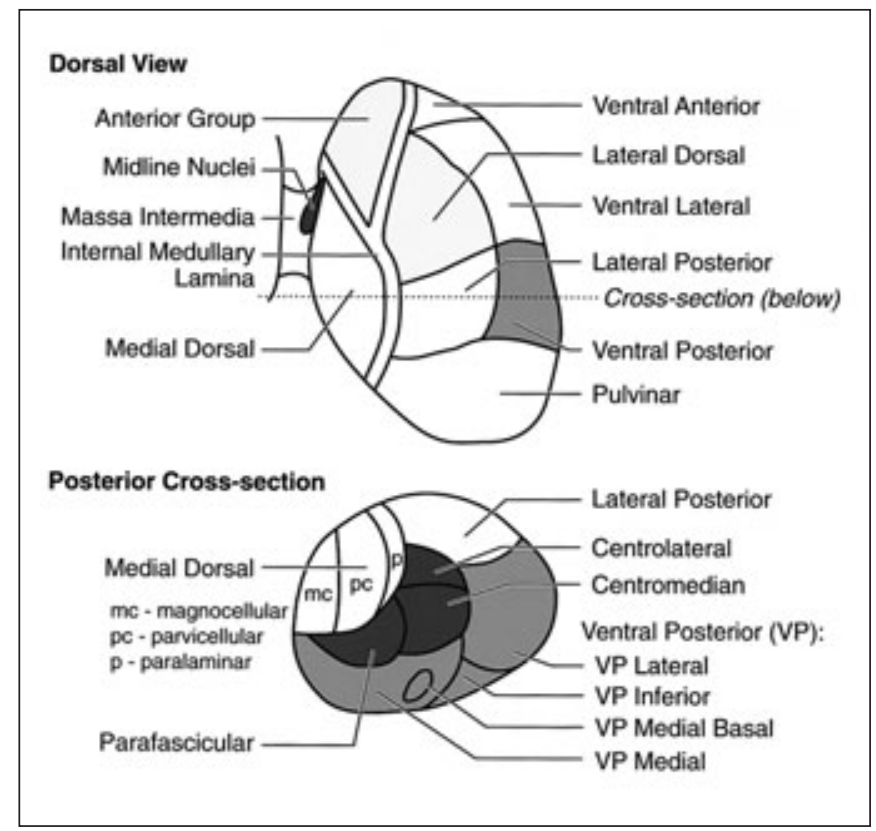

Figure 2. Thalamic nuclei. ${ }^{63}$ The anterior nuclear group and lateral dorsal nuclei (light shade) project to the posterior cingulate cortex (areas 29, 30, 23, 31). The ventral posterior (VP) nucleus (medium shade) is subdivided into nuclei of which the VP medial, lateral and inferior project to somatosensory areas S1 and S2 (see text). The midline nuclei (dark shade shown in dorsal view) and centrolateral, centromedian and parafascicular nuclei (dark shade in posterior crosssection) project to the anterior cingulate cortex (areas 25, 24, 33, 32). The magnocellular portion of the medial dorsal (mediodorsal) nucleus has prominent connections with the medial and orbital prefrontal cortex and amygdala (see Figure 6) whereas the parvicellular part has prominent connections with the dorsolateral prefrontal region. (Modified form Figure 11-4, Kiernan J. Barr's Human Nervous System ${ }^{63}$ with permission).

thalamus are divided into lateral sensory-discriminative and medial motivational-affective systems. As shown in Figure 2, the lateral system is formed by the ventral posterior (VP) nucleus consisting of four subnuclei: (i) the VP medial nucleus containing somatosensory representation of the contralateral face and intraoral structures projecting to the S1 somatosensory area, (ii) the VP lateral nucleus containing somatosensory representation from the remainder of the contralateral body surface that is also connected to S1, (iii) the VP inferior nucleus that probably projects to $\mathrm{S} 2$ somatosensory area, and (iv) VP medial basal nucleus that represents taste. ${ }^{57,73}$ The medial system (Figure 2) is composed of the intralaminar (centromedian, centrolateral and parafascicular nuclei) and midline nuclei. ${ }^{10,11,12,74,75}$ The lateral group of nuclei projecting to the cortical somatosensory areas S1 and S2 serve mainly to identify the location and character of pain whereas the medial group projects to the cingulate cortex for its affective content. ${ }^{9,10,76,77}$ The medial thalamus, however, does appear to have some discriminatory capacity in terms of pain intensity. ${ }^{78}$

In an attempt to locate neurons that were electrophysiologically and selectively responsive to pain, $\mathrm{Casey}^{79}$ found widespread responses to peripheral noxious stimuli in the monkey thalamus and concluded that activity relevant to pain was not restricted to exclusively nociceptive neurons. Nevertheless, in human subjects, spontaneous noxious stimuli do produce neuronal discharges in the dorsal horn of the spinal cord that are transmitted to the ventral posterior nucleus of the thalamus and the midline and intralaminar thalamic nuclei, albeit not exclusively ${ }^{80-83}$ Indeed, electrophysiological studies have shown distinct populations of neurons in the ventral posterior nucleus, within regions where neurons respond mainly to innocuous cutaneous tactile stimuli, that selectively respond to specific innocuous and/or painful (notably mechanical, hot or cold thermal) inputs. ${ }^{84-86}$ Lenz et al ${ }^{84}$ were even able to evoke pain by means of threshold microstimulation at sites where neurons in the ventral posterior nucleus responded to noxious heat. Coghill et al. ${ }^{26}$ compared PET responses in human subjects to heat pain and robust, but innocuous, vibrotactile stimuli (touch). Whereas pain was associated with increased activity in the thalamus it was not observed with vibration, although electrical discharges in the ventral posterior lateral nucleus in response to tactile stimuli have been previously well described. ${ }^{87}$ The difference with PET may depend upon intensity of a stimulus inasmuch as pain may not only recruit more neurons but excite both the medial and lateral systems of the thalamus (Table 1). Davis et al,,$^{39}$ using fMRI, found that cutaneous responses to tactile stimuli were restricted to the contralateral ventral posterior nucleus of the thalamus, whereas heat and cold pain activated both medial and lateral thalamic regions.

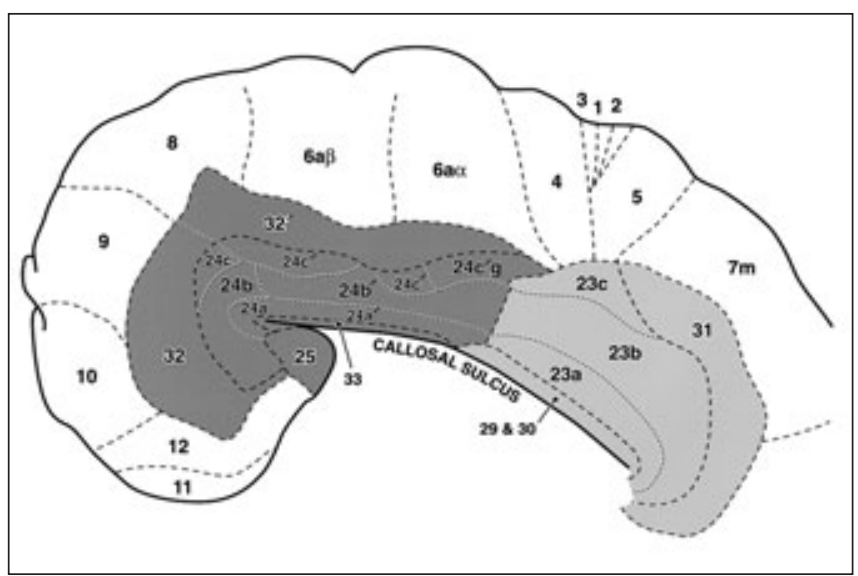

Figure 3. Flat map of the human cingulate cortex (whole shaded area) with superimposed cytoarchitectural cortical areas from a single subject. The anterior cingulate region (dark shade) consists of Brodmann areas 25, 24, 33, and 32 including subdivisions (lettered and with primes). ${ }^{88}$ The posterior cingulate region (light shade) is composed of areas 29, 30, 23, and 31 including subdivisions with corresponding letters. Area $24 c$ 'g represents the primitive gigantopyramidal area of Braak $^{160}$ which he identified with the cingulate skeletomotor area. (Modified from Figure 5 in Vogt BA et al. Human Cingulate Cortex: Surface Features, Flat Maps, and Cytoarchitecture, J Comp Neurol 1995; 359:490-506. ${ }^{89}$ Adapted by permission of Willey-Liss, Inc., a subsidiary of John Wiley and Sons Inc.). 


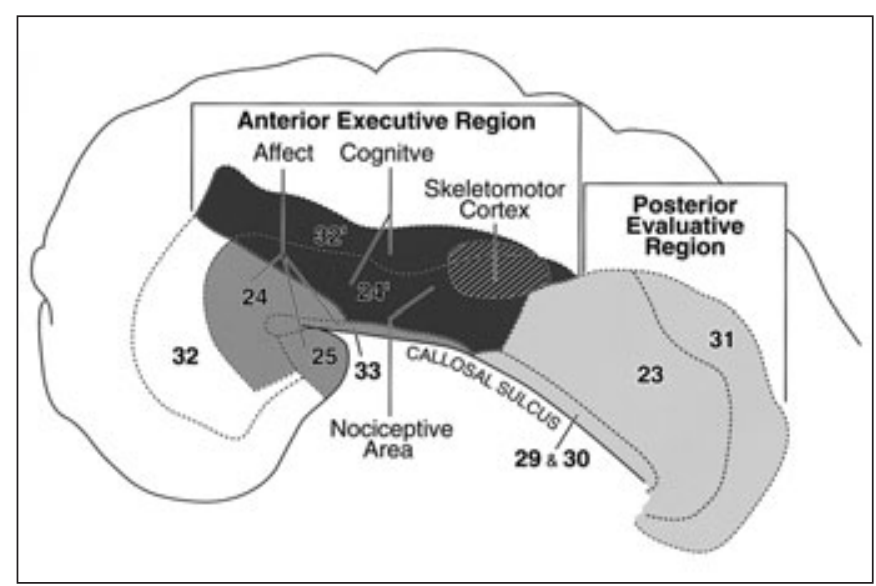

Figure 4. Flat map as in Figure 3 showing functional regions of the human cingulate cortex consisting of anterior executive and posterior evaluative regions. ${ }^{95}$ The area shown as the skeletomotor cortex in cingulate sulcus corresponds to the caudal cingulate zone (gigantopyramidal area) shown in Figure 7. The visceromotor region in areas 24 and 25 is less well defined.

\section{Cingulate cortex}

The cingulate cortex is a prominent and functionally complex part of the limbic system which extends the length of the corpus callosum from the genu backward above and adjacent to the corpus callosum (Figure 3). Cytoarchitecturally, it is divided into an anterior part which has an agranular appearance similar to motor cortex with a prominent layer Va, and a posterior part consisting of granular layers II and IV typical of areas receiving primary afferent input. ${ }^{88,89}$ The two parts of the cingulate cortex are further subdivided into specific areas..$^{18,77,89}$ Each of the areas of the anterior part (areas 25, 24, 33, 32) and posterior part (areas 29, 30, 23 and 31) receive and reciprocate very different cortical, thalamic and other subcortical inputs (Figure 3). ${ }^{18,90}$ In general, the anterior cingulate cortex receives a relatively small afferent supply from other cortical areas whereas the posterior cingulate has extensive input from the frontal, parietal, temporal and occipital lobes. Nevertheless, the two cingulate parts are well interconnected. Thalamic projections also differ with the anterior cingulate cortex receiving afferents mainly from the midline and intralaminar thalamic nuclei while the posterior part derives its input particularly from the lateral dorsal and anterior group of thalamic nuclei, all of which are correspondingly reciprocated (Figure 2). ${ }^{91}$ Differences in input are especially striking in connections with the amygdala which reciprocally projects to the anterior cingulate areas 33, 25 and the rostral part of 24 but to neither the caudal part of area 24 nor the posterior cingulate cortex.$^{90}$ As discussed below, the major role of the amygdala is the storage of emotional memory, and its connections with the anterior cingulate region, where emotional responses are generated, may be to relate ongoing with past emotional experience. In PET studies of pain the anterior cingulate cortex, and to a lesser degree the posterior part, are highly responsive to noxious stimuli (Table 1).

As differences in cytoarchitecture and connections would suggest, the anterior and posterior cingulate cortices also have quite different functions. ${ }^{92}$ The anterior part is viewed as having executive responsibility (vis à vis motor function) whereas the posterior part has more of an evaluative role (Figure 4). ${ }^{28,77,93-95}$ Moreover, the anterior cingulate cortex is further subdivided into "affect" and "cognitive" parts. The rostral "affect" subdivision (areas 33, 25 and rostral area 24) is reciprocally connected to the amygdala, hypothalamus and autonomic brain stem motor nuclei, and its function, on the basis of electrical stimulation and surgical ablation studies, is to generate emotional responses. 95 The caudally located "cognitive" subdivision (areas 24' and 32') is considered to be mainly responsible for skeletomotor behaviour and nociception (see also Figure 7). ${ }^{95}$ As discussed above, the midline and intralaminar nuclei of the thalamus (motivational-affective system) project to the anterior cingulate region and those neurons which receive afferents from the spinothalamic tract that originate from cells in the dorsal horn responding to noxious stimuli project to the nociceptive region of the cingulate cortex that is located in the dorsal part of area 24 in the vicinity of $24 c^{\prime} \cdot{ }^{18,77}$ As observed by Rainville et al. ${ }^{96}$ pain affect, i.e. the discomfort of pain, despite evidence in the monkey that somatosensory areas 1 and 2 receive direct nociceptive input, is encoded in the human anterior cingulate and not in the S1 and S2 somatosensory cortices. The latter areas are essential to the location and character of pain for appropriate avoidance responses. The posterior cingulate cortex has widespread input but significant reciprocal connections with the posterior parietal region, visual cortex, striatum and thalamus and, together with the anterior cingulate cortex - particularly the caudal portion of area 24 which receives parietal and the bulk of the posterior parahippocampal projections going to area $24-$ may participate in the formation and recall of long-term factual memory and avoidance learning. ${ }^{26,29,94,97}$

A number of techniques have demonstrated nociceptive responses in the cingulate gyrus accompanying noxious peripheral stimulation. Vaccarino and Melzack ${ }^{98}$ could inhibit peripherally-induced severe pain by the injection of lidocaine into the fasciculus cinguli of rats. Sikes and $\operatorname{Vogt}^{99}$ used electrophysiological recording techniques to observe excitatory evoked potentials in area $24 \mathrm{~b}$ of the anterior cingulate cortex of rabbits in response to noxious transcutaneous electrical, mechanical and thermal stimuli. They concluded that the cingulate nociceptive responses were mediated through the medial and intralaminar nuclei of the thalamus and noted lidocaine injections into the medial thalamus abolished these responses. It is noteworthy in this context that opioid innervation is particularly highly concentrated in the midline and anterior intralaminar regions of the thalamus and there is also an unusually high density of opioid receptors in the anterior cingulate cortex which may have a regulatory function in situations of chronic pain..$^{9,77,89,100,101}$ Vogt et al. ${ }^{77}$ found that nociceptive area of the cingulate cortex in the rhesus monkey brain was, similar to the rabbit, probably located at the dorsal part of area 24. Surgical cingulotomy in man, as noted earlier, has been performed with reported success in the relief of intractable chronic musculoskeletal pain but was unsuccessful with thalamic pain due to old stroke. ${ }^{102}$ In PET studies, area 24 of the human anterior cingulate cortex shows the most consistent increase in $\mathrm{rCBF}$ in response to noxious stimulation although it is occasionally unresponsive (Table). The location of cognitive 
(attention-related) and pain-related activations demonstrated on fMRI correspond to the anterior cingulate areas as described above by others. ${ }^{37,95}$

\section{SOMATOSENSORY, ASSOCIATION CORTICES AND SUBCORTICAL NUCLEI}

In addition to the cingulate cortex, other regions of the brain show significantly increased nociceptive PET responses, notably the somatosensory area S1, thalamus, insula and basal ganglia (Table). Other areas, such as the parietal cortex, show both increased and decreased activity, whereas in the frontal eye field (area 8), posterior cingulate region and occipital cortex almost all activity is significantly decreased. The main connections within and between these regions as they may integrate nociceptive responses are as follows.

\section{Somatosensory (S1 and S2), parietal, occipital and temporal cortices}

Somatosensory area S1, visual and auditory cortices in the parietal, occipital and temporal lobes project to their respective adjacent association fields and to the frontal lobe. ${ }^{103,104}$ As described by Jones and Powell, ${ }^{103}$ in primates each of the major sensory areas, through a cascading series of connections, converge at first as unimodal sensory areas and then as polysensory regions (Figure 5). The shift is toward different, more highly advanced sensory association and motor cortices in the parietal and frontal lobes. For example, in the somatosensory system as shown in Figure 5, sensory information from SI is processed in parietal area 5 and then in the posterior parietal area 7 where unimodal topographical boundaries are merged to form a body surface image. ${ }^{104}$ From area 7 , two or more unimodal "high level" somatosensory association cortices merge to form polysensory zones on the floor of the superior temporal sulcus, cingulate cortex and parahippocampal cortex. Additional recipients of polysensory convergence are located in the lateral aspect of the orbitofrontal cortex, the temporal and frontal poles and amygdala. ${ }^{103,104}$ As stated above, there is a stepwise procession of reciprocal connections from the parietal sensory association areas to the frontal motor and prefrontal regions, toward the frontal pole. Frontal areas are, in effect, reciprocally interlocked with each step of the series of polysensory connections beginning with area 5 , the first local projection area of the primary sensory cortex. ${ }^{103}$

Friedman et al. ${ }^{105}$ studied area S2 in the monkey and observed that its fibres were interconnected with the postcentral cortex (areas 1,2,3), areas 5 and 7 in the parietal lobe and the insula (granular and dysgranular cortex - see below). All of these areas have access to the amygdaloid cortex and hippocampal formation, the latter probably through relays from the perirhinal cortex or parahippocampal gyrus. ${ }^{104}$ In a fMRI study of 12 subjects, Davis et al. ${ }^{39}$ found that responses in S2 to a cutaneous tactile stimulus was $100 \%$ whereas responses to noxious heat or cold occurred in only half of the cases. Despite its small area the S2 somatosensory cortex may have an important influence on pain perception although this may be mainly in a tactile component that is distinct from $\mathrm{S} 1 .^{70}$

\section{Insula}

The insula is highly active in relation to pain, especially in its affective content, and has a very large spectrum of cortical

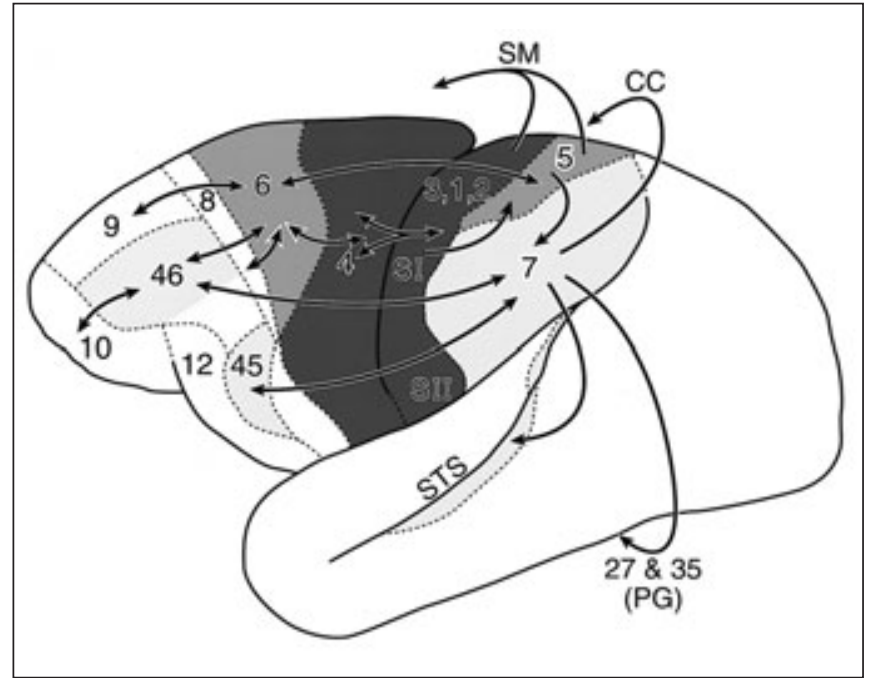

Figure 5. Converging somatosensory and reciprocal motor connections (arrows) in the monkey cerebral cortex are shown as described by Jones and Powell. ${ }^{103}$ Pathways are reciprocal between parietal and the frontal lobes and between frontal areas. However, projections are not returned within the parietotemporal cortex where unimodal sensory input is merged to form increasingly "higher level" polysensory regions. Also, projections from Brodmann areas 5 and 7 to the supplementary motor area $(S M)$ and cingulate cortex $(C C)$ are not reciprocated. STS superior temporal sulcus, a major high level sensory association area; $P G$ - parahippocampal gyrus that includes area 27 (subiculum) and part of the adjacent area 35 that are involved in processing memory.

connections that can be divided into two groups. The posteriordorsal insula (granular and adjacent dysgranular cortex) has predominantly sensory and motor connections that include the somatosensory cortices $\mathrm{S} 1$ and $\mathrm{S} 2$, parietal areas 5 and $7 \mathrm{~b}$, auditory area, visual area, prefrontal and orbitofrontal cortices, and premotor area $6 .{ }^{103}$ Schneider et al. ${ }^{106}$ maintain that the granular field of the posterior dorsal insula is a predominantly modality-specific cortical area for the processing of somatosensory information, rather than visual and auditory inputs, and serves as a high-order link in the somatosensorylimbic pathway. The anterior-ventral insula (dysgranular and agranular-periallocortical cortex) is extensively connected with limbic, paralimbic, olfactory, gustatory and autonomic structures. Mesulam and Mufson, ${ }^{107}$ noting that the insula has massive connections with the somatosensory areas and amygdala (a limbic structure), suggest that the insula may have a role in motivational-affective valuation of sensory experience. Electrical stimulation of the anterior insula produces autonomic respiratory, cardiovascular and gastric motor responses and, in addition to having access to the amygdaloid complex, receives afferents from the anterior cingulate cortex including area 24 and caudal orbitofrontal cortex, both of which also have autonomic functions. ${ }^{108-110}$ Coghill et al. ${ }^{26}$ observed on PET scanning that heat pain did not activate the posterior insula but did activate the anterior insular cortex. As these authors point out, nociceptive activity, per se, is not a feature of the insula but "pain-related activation in anterior insula may reflect circuitry involved in affective and reactive components of pain". Consistent with the 
above observations, Davis et al. ${ }^{39}$ found that the posterior (somatosensory) area of the insula is activated on fMRI by innocuous tactile stimulation and the anterior area by noxious thermal stimuli.

\section{Basal ganglia}

The basal ganglia encode and initiate basic movement patterns expressed through the premotor and primary motor areas and show frequent activation to noxious stimuli in PET studies (Table). Although they receive substantial projections from the cerebral cortex these are not reciprocated directly but relayed back through the thalamus. ${ }^{111,112}$ The connections of the basal ganglia can be divided into two groups composed of either input or output nuclei. ${ }^{112}$ The caudate nucleus, putamen and nucleus accumbens are input nuclei and the globus pallidus and pars reticulata of the substantia nigra are output nuclei. The input nuclei receive a rich input from the prefrontal cortex, motor, sensory and limbic cortices and the output nuclei send axons to the thalamus and from there projections loop back to the cortex (Figure 6). ${ }^{111}$

The nucleus accumbens is a main component of the ventral striatum processing information from affiliated cortical areas, especially the medial prefrontal, insular, entorhinal and hippocampal cortices, and through which most of the limbic cortical areas gain access to the basal ganglia circuitry. ${ }^{112}$ Deniau et al. ${ }^{112}$ found that the pars reticulata is a major link between the nucleus accumbens and the prefrontal cortex via the mediodorsal and ventromedial thalamic nuclei. The nucleus accumbens also projects to the ventral pallidum and input is similarly relayed to the mediodorsal nucleus of the thalamus. Brown and Marsden ${ }^{113}$ have recently proposed that the basal ganglia are not structures exclusively linked to motor function but support a basic attentional mechanism in the prefrontal region facilitating the calling up of motor programmes and thoughts.

\section{Amygdala, hypothalamus and periaqueductal gray}

Whereas the amygdala has a major role in emotional behaviours and is likely involved in reactions to pain, it has almost consistently failed to show a significant PET response to noxious stimuli, although situations arousing fear alone have produced increased activity. ${ }^{4,114,115}$ Galvez et al. ${ }^{116}$ observed a release of noradrenaline in the amygdala in response to mildly painful stimuli in rats that was perhaps fear-related. In contrast, the periaqueductal grey to which the amygdala is directly connected shows increased activity in a third of the reported nociceptive PET studies.

The amygdala is located at the tail end of the caudate nucleus in the dorsomedial part of the temporal lobe and contains a dozen or so key nuclei with extensive cortical and subcortical connections. ${ }^{117}$ Its most prominent cortical sensory projections are from the anterior inferior and superior temporal cortex and posterior insula that are mainly advanced visual, auditory and somatosensory-associated areas. ${ }^{117}$ Thus, sensory integration in the amygdala is evidently a major part of its function, and from

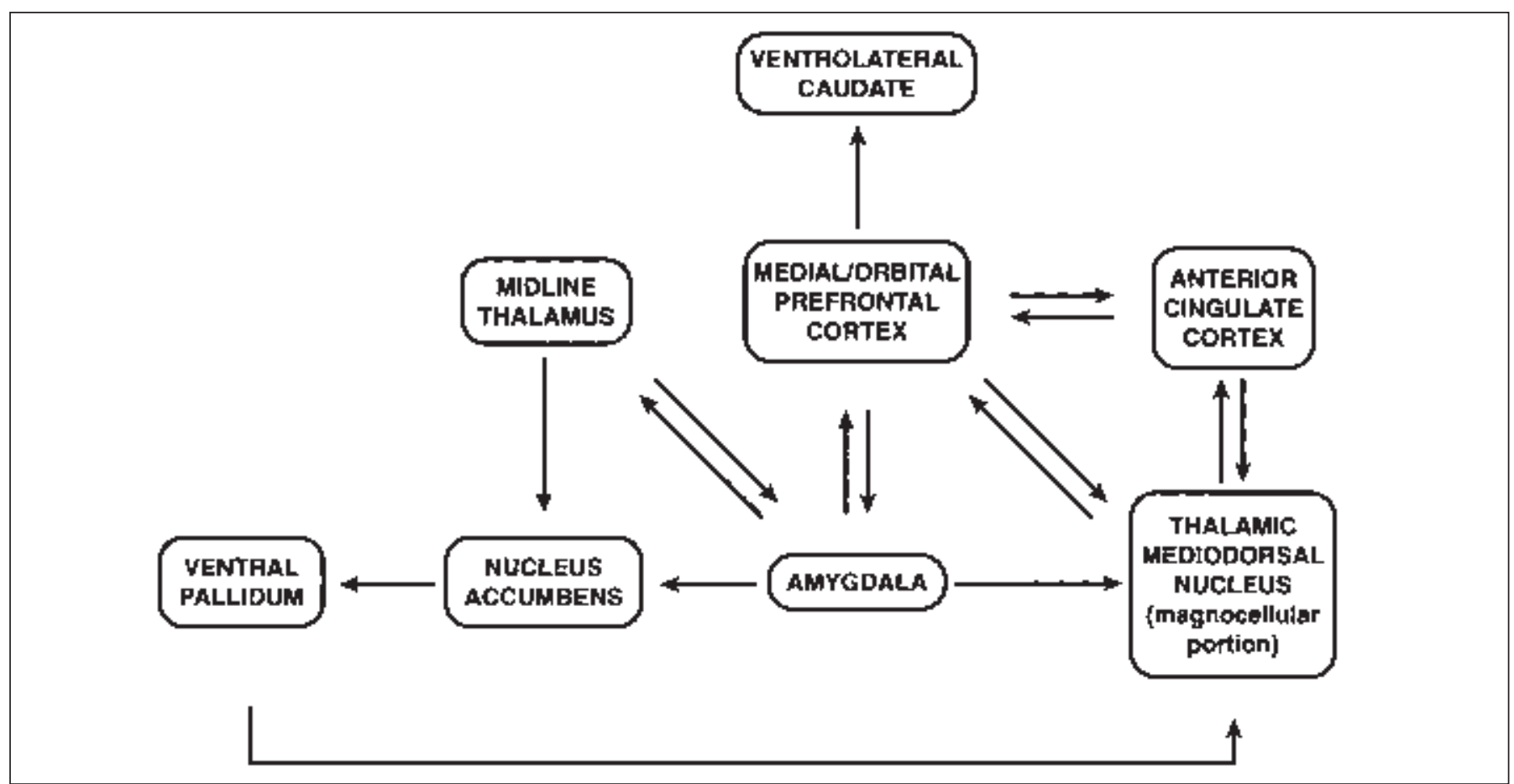

Figure 6. Schematic of some connections of amygdala and medial and orbital prefrontal cortex related to visceromotor functions. As described by Amaral et al. ${ }^{117}$ the amygdala has extensive reciprocal connections with this region of the prefrontal cortex and also projects to the mediodorsal nucleus of the thalamus that in turn sends fibres to the same frontal region to which the amygdala projects. The amygdala is also connected with the midline thalamic nuclei and nucleus accumbens where its influence is again returned by way of the globus pallidus and mediodorsal nucleus of the thalamus to the prefrontal cortex. Note that cortical and subcortical connections with the basal ganglia are reciprocated indirectly to their source via the thalamus. 
the arrangement of the nuclei, it appears to have interfacing sensory and motor systems. There are substantial reciprocal connections between the amygdala and area 24 of the anterior cingulate cortex but the cortical regions receiving the heaviest amygdaloid afferents, with much less in the way of reciprocal projections, are the medial and lateral orbitofrontal cortex, medial wall of the frontal cortex and agranular insular cortex (Figure 6). ${ }^{107,118,119}$ All of these regions, directly and/or by way of the amygdala, have major hypothalamic and autonomic brain stem connections. ${ }^{117}$ Efferents from the amygdala descend into and through the midbrain, pons and medulla innervating a number of structures implicated in autonomic control, notably the periaqueductal gray, nucleus of the solitary tract, reticular formation and the dorsal nucleus of the vagus. ${ }^{117,120,121}$

The function of the amygdala has been extensively explored through electrical stimulation and spontaneous or induced ablation. Electrical stimulation of the amygdala elicits extreme emotional behaviour consisting of anger and autonomic responses such as accelerated heart rate, rise in blood pressure and pupillary dilatation. ${ }^{122-124}$ Graeff et al. ${ }^{125}$ and others maintain that a longitudinally organized neural system linking the amygdala, medial hypothalamus and periaqueductal gray matter is integral to particular behavioural and physiological manifestations of defensive reactions, such as the fight or flight response, when an individual is subjected to threat of injury or pain. ${ }^{126-130}$ The amygdala also has a major role in learning and the formation of long-term emotionally influenced memories referred to as "emotional memory". ${ }^{131-137}$ The hippocampus is familiar as the main site for neuroplasticity mediating the acquisition and extinction of declarative or factual memory and the amygdala likely has a similar neuroplastic function in relation to conditioned fear. ${ }^{131}$ The amygdala and hippocampus are also alike in showing very little response to nociception in the PET studies which may be due to the role of both in memory storage and recall rather than first line defence against injury except, as has been demonstrated with the amygdala, during fearful or threatening situations..$^{114,115}$

\section{Prefrontal cortex}

Numerous areas in the prefrontal cortex respond to painful stimuli indicating its highly active involvement, especially area 10 which lies at the frontal pole (Table). The prefrontal cortex, including the orbitofrontal region, has inputs from various sectors of the cerebrum which merge into large overlapping areas. ${ }^{138}$ The area of cortex which defines the prefrontal region is actually indefinite because of a lack of reliable cytoarchitectonic boundaries and species variability. However, this difficulty is partly resolved by using afferent connections, especially those relayed through the mediodorsal nucleus of the thalamus, which sends fibres to all areas of the frontal cortex as defined by topography and cytoarchitecture as being likely prefrontal. ${ }^{139,140}$ The mediodorsal nucleus has two major and quite different components, one of which, the magnocellular medial part, is connected mainly to the orbital and medial prefrontal cortex and the other, the parvicellular lateral portion, projects essentially to the dorsolateral prefrontal convexity (see Figure 2). ${ }^{140}$ These two well interconnected prefrontal regions also have very different functions and certain selected areas of projection. ${ }^{141,142}$ The prefrontal medial and orbitofrontal areas, to which functions related to the autonomic state of the organism have been ascribed, project their fibres predominantly to the magnocellular portion of the mediodorsal nucleus, hypothalamus, ventromedial caudate nucleus, amygdala and autonomic brain stem nuclei. ${ }^{140}$ The dorsolateral prefrontal area, identified with cognitive and spatial functions, is connected predominantly with the parvicellular part of the mediodorsal nucleus, dorsolateral caudate nucleus, hippocampus and neocortex. The cingulate cortex, which is essential for the perception and response to pain, has abundant and widespread projections to the prefrontal dorsolateral and orbitofrontal cortices. ${ }^{143}$ The prefrontal cortex in turn projects to most or all parts of the cingulate cortex with the dorsomedial and dorsolateral prefrontal cortex projecting preferentially to the anterior cingulate region..$^{90,119,144}$ Almost all connections to the prefrontal cortex are reciprocal, a notable exception being, as discussed above, the basal ganglia which relay feedback by way of the thalamus (Figure 6). ${ }^{111,112,145}$

The dorsolateral prefrontal cortex (areas 9 and 46) is apparently involved in selecting and maintaining behaviourally relevant information, called "working memory" (see cortical map, Figure 1). ${ }^{45,47,146,147}$ Injury to this region would likely cause impairment in abstract reasoning, complex problem solving and future planning. Access to the hippocampal formation by the dorsolateral prefrontal cortex, as stated by Goldman-Rakic et al. ${ }^{148}$ probably provides the means whereby stored memories related to current memories are retrieved. Damasio ${ }^{46}$ also found that patients with lesions in the ventral and medial prefrontal region present with "personal and social impairments of decision-making" without alteration in intellect, attention or working memory. This prefrontal region is related to central autonomic control, suggesting that impairment in these cases may have produced an altered or unaroused "state of mind". ${ }^{149,150}$ The role of the prefrontal frontopolar region (area 10) has recently been described as mediating a function of holding in mind primary goals while exploring secondary goals as part of the process of planning and reasoning. ${ }^{151}$

Understanding the functions of the prefrontal cortex has, until very recently, depended upon changes produced by frontal lobe injury or surgical procedures such as prefrontal lobotomy or leucotomy. Certain prefrontal leucotomy procedures were used to provide relief for emotional illness or intractable pain in cases of metastatic carcinoma, causalgia and neuropathy. ${ }^{152,153}$ Depending upon where in the frontal lobe the leucotomy was made, pathways between the prefrontal cortex and the cingulate cortex and/or thalamus (mediodorsal nucleus of the thalamus and midline and intralaminar thalamic nuclei) or between the thalamus and cingulate cortex, were severed. ${ }^{16,154-156}$ It was on the basis of such pathological findings that Foltz and White ${ }^{15}$ elected to section the cingulum fasciculus in cases with intractable pain. Because patients subsequently maintained that they still experienced pain but it was no longer unpleasant suggests that the affective component of the nociceptive experience had been removed, comparable to what had been earlier achieved with prefrontal leucotomy.

\section{PREMOTOR, SUPPLEMENTARY AND PRIMARY MOTOR SYSTEMS}

The premotor, supplementary motor and primary motor cortices responded to nociceptive stimuli in some PET studies 


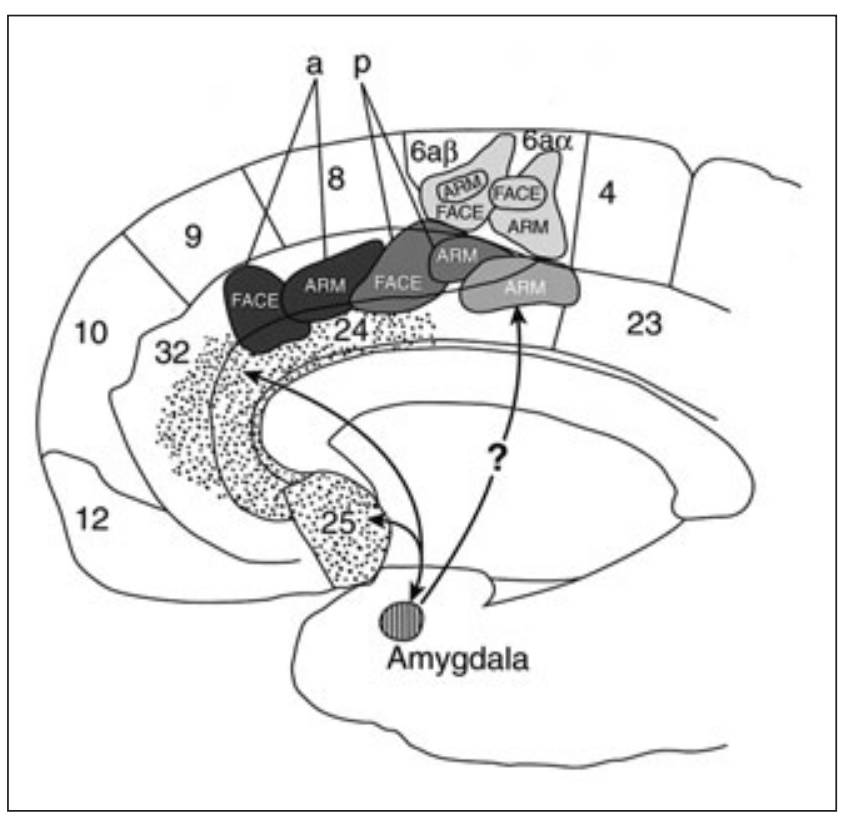

Figure 7. Two premotor regions, the supplementary motor area (SMA) and the cingulate motor area, are located on the medial wall of the human cerebral hemisphere and are well interconnected with one another and also with the premotor area 6 on the lateral hemispheric surface and the primary motor cortex. The SMA (light shade) is divided into (i) a rostral pre-SMA that is located in area $6 a \beta$ for complex (cognitive-motor) tasks and (ii) the SMA proper in area $6 a \alpha$ for simple (repetitive) tasks. ${ }^{157}$ The cingulate motor area has (i) a large rostral cingulate zone (dark shades) consisting of two face and arm areas (a and p) for complex tasks, and (ii) a smaller caudal cingulate zone (lighter shade, shown here as arm area only) for simpler tasks. The caudal site corresponds to Braak's ${ }^{160}$ gigantopyramidal area and responds to painful stimuli. ${ }^{157}$ The dotted cingulate areas represent the distribution of reciprocal amygdaloid connections (areas 33, 25 and rostral part of 24 with some extension into area 32). A proposed connection of the amygdala with cingulate motor area is shown. (SMA and cingulate motor areas are modified from Figures 4 and 5 in Picard and Strick ${ }^{157}$ by permission of Oxford University Press).

(Table) and, whereas a response in the supplementary and primary motor cortices was always increased, it was either increased or decreased in the premotor cortex. Included in the premotor system, but not always seen in the PET studies because it was not readily distinguishable from other parts of area 24 of the anterior cingulate region, was the cingulate motor cortex. All premotor areas project to the primary motor cortex and to the spinal cord. ${ }^{157}$ The primary motor area (area 4) projects to the spinal cord but is programmed for only simple actions and therefore the premotor cortices are required to direct the primary motor neurons in the execution of particular, more complicated, movements (Figures 5 and 7). ${ }^{158}$ The purpose, initiative and facilitation of movements depends on the prefrontal cortex but this does not project to the primary motor cortex nor to the spinal cord and therefore is dependent upon its abundant connections with premotor areas. ${ }^{158,159}$

Although it has received very little attention the cingulate motor cortex may have major importance in the motor responses to pain. In the anterior cingulate region, there are two distinctive motor areas, a skeletomotor (premotor) area 24c' in the lower bank of the cingulate sulcus and an autonomic motor (visceromotor) region located in the ventral part of the gyrus (Figures 4 and 7). ${ }^{119}$ The cingulate skeletomotor cortex in man was described by Braak $^{160}$ as a primordial limbic motor area. It actually consists of probably three closely related and interconnected premotor areas projecting abundantly, somatotopically and reciprocally to the frontal premotor area 6 on the lateral surface of the hemisphere, supplementary motor area on the medial surface and the primary motor cortex (Figures 1 and 7). ${ }^{119,157,161-163}$ The cingulate skeletomotor areas are also heavily connected with the dorsolateral prefrontal cortex, similar to the other premotor areas, and it has, as well, modest input from the orbitofrontal cortex and parietal lobe. ${ }^{119,163}$ Also, the cingulate motor cortex, again similar to other premotor regions, is the target for efferents from the basal ganglia and cerebellum, with additional afferents from the temporal pole, entorhinal and perirhinal cortices and posterior parahippocampal cortex. The cingulate autonomic motor cortex in areas 24 and 25 project to the amygdala, hypothalamus, periaqueductal gray, brain stem reticular formation, dorsal motor nucleus of the vagus and nucleus of the solitary tract. ${ }^{164}$

The anterior cingulate cortex in man has remarkably little if any significant connection with the cingulate skeletomotor cortex in the cingulate sulcus, frontal premotor areas, primary motor cortex or spinal cord. ${ }^{163,165}$ As raised by Dum and Strick ${ }^{163}$ the lack of evidence for the cingulate skeletomotor areas having substantial interconnections with the cingulate gyrus would indicate that motor expression must occur, directly or indirectly, by other known projections from area 24 . A most likely route would be indirect, such as via the prefrontal cortex or amygdala. The amygdala has abundant connections with the anterior cingulate cortex but does not project to the primary motor cortex nor substantially to other skeletomotor areas. ${ }^{166}$ Nevertheless, an amygdaloid connection with the cingulate motor cortex, which is well connected with the frontal premotor, supplementary and primary motor areas, might provide a route for skeletomotor response to pain and fear for both the amygdala and the anterior cingulate cortex (Figure 7). Van Hoesen et al. ${ }^{119}$ suggest "that the cortex along the lower bank of the cingulate (where the cingulate motor cortex is located) provides a pivotal anatomical interface between the traditional (premotor and primary motor) isocortical motor areas and traditional limbic and multimodal association areas of the primate cerebral cortex". It is possible, therefore, that the cingulate cortex and amygdala, as high order limbic structures, may have at some time (phylogenetically) depended almost entirely upon the cingulate motor cortex for their expression, including responses to pain.

\section{CONCLUDING REMARKS}

Pain is a signal of bodily injury that is normally generated in peripheral nerve nociceptors but also occurs pathologically within the nervous system in association with peripheral, spinal or cerebral disorders such as with neuromas, amputation, strokes, etc. ${ }^{5,6,167}$ In this review, the objective was to integrate current understanding of cerebral connections between cortical regions and nuclei with multiple areas of response in PET and fMRI studies to noxious stimuli in an attempt to define a system of nociceptive afferent and efferent pathways. The proposed nociceptive system, as shown schematically in Figure 8, 


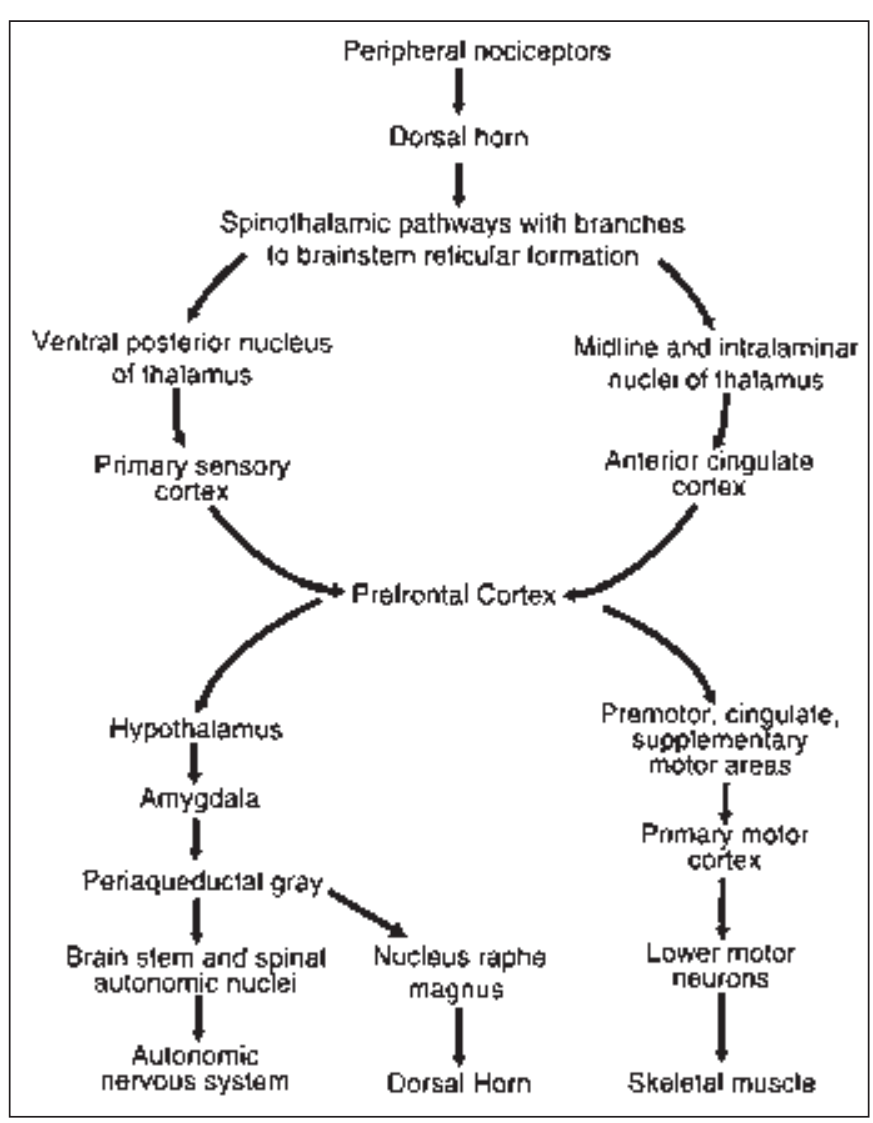

Figure 8. Schematic version of a proposed afferent and efferent nociceptive pathway. Only certain key components and not contributing inputs from other areas of brain are shown. In the efferent pathway the projection of the periaqueductal gray to the nucleus raphe magnus represents part of an inhibitory system acting upon the dorsal horn (see text).

demonstrates only the principal structures as derived from the studies excluding contributing inputs from other loci or connections that may act as possible lower level nociceptive "short circuits".

The response of the various cerebral loci in PET to noxious peripheral stimulation is quite variable in activity (increased and/or decreased) and frequency. This could have many causes including differences in experimental technique and, as has been recently demonstrated with fMRI, intersubject variability. ${ }^{39}$ Also, as shown in a fMRI study by Ploghaus et al. ${ }^{168}$ the anticipation of pain and the experience of pain activate different regions although these were in close proximity to one another. Nevertheless, some structures have shown a high incidence of increased and very little or no decreased rCBF activity with PET, such as the anterior cingulate region, suggesting a high state of neuronal activity. Decreased responses (most consistently the posterior cingulate region, frontal eye field area 8 and occipital cortex) have been difficult to explain although they would seem to represent a relatively passive state of neuronal activity. This is supported in the highly variable (increased and decreased) responses in the parietal lobe and prefrontal frontopolar area 10, both high order association cortices where, as described by Koechlin et al. ${ }^{151}$ functions may at times be in a relatively passive state, as when listening and reading, versus periods of active exploration and processing as required during planning and reasoning. As commented upon earlier, the amygdala rarely reacted to pain during PET studies in contrast to the effect of fear or anxiety that may have been due to precautionary efforts to avoid fear as an experimental condition. ${ }^{114,115}$ It is likely, nonetheless, that the amygdala is active, if not visibly, in retrieving emotionally based memory during painful experiences. The experience of pain, therefore, is accompanied by changes in rCBF in many areas of the nervous system and whether these represent increased or decreased neuronal activity, it is assumed they are structures that are among the most affected during pain. Accordingly, in this context, they can be viewed as significant components of a nociceptive system.

The proposed nociceptive afferent pathway as shown in Figure 8 extends from the peripheral nerves to the thalamus, anterior cingulate and somatosensory cortices to the prefrontal cortex. Many cerebral structures during this phase contribute to the interpretation and the integration of information such as the posterior parietal cortex, posterior cingulate cortex, insula, amygdala and hippocampal formation, all of which are interconnected with the prefrontal cortex. The assembly of information and response to a painful experience may depend largely upon the prefrontal cortex because of its large, advanced sensory and motor input and capacity to provide such functions as sustained attention, spatial working memory, capacity for decision-making, holding information and the programming of skeletomotor and autonomic behavioural responses. Thus, the prefrontal region is provided with comprehensive and evaluated information, both current and past, the latter through the hippocampus (factual memory) and amygdala (emotional memory). In the efferent pathway a conscious behavioural response to pain is initiated in the prefrontal cortex, notably in its frontopolar and dorsolateral aspects, which provide direction to the adjacent premotor areas. The latter are then programmed to orchestrate the primary motor cortex and lower motor neurons to execute the appropriate skeletomotor responses to either limit or avoid painful threat or injury. Simultaneously autonomic efferent responses to the same threat or injury are initiated in the prefrontal medial and orbitofrontal cortex to the hypothalamus, amygdala, periaqueductal gray, nucleus raphe magnus, brain stem and spinal autonomic neurons.

Why is the cingulate cortex so significantly involved in pain perception? It is possible that nociceptive integration and the recognition and evaluation of pain was at one time, prior to neocortical development, limited to the limbic nervous system, notably the hippocampus, cingulate cortex, cingulate skeletomotor and autonomic motor areas and amygdala, that represented the highest order cognitive, afferent and efferent levels. Accordingly, the prefrontal cortex and other parts of the neocortex may represent additions to an otherwise primordial limbic pain system which might still be capable of functioning autonomously but with prior aversive conditioning involving prefrontal and other neocortical input. ${ }^{169,170}$ Indeed, direct nociceptive spinal pathways extending from the dorsal horn to the limbic system, especially to various nuclei in the thalamus and hypothalamus bilaterally, have been described that may still 
function in a nociceptive reflex capacity, i.e. rapid withdrawal from painful stimuli. ${ }^{72}$

In summary, there have been recent major developments in neuroimaging of areas of brain predominantly responding to painful stimuli and in the tracing of central nervous system connections between these areas. A process for pain perception and response has been proposed in which central nervous system afferent and efferent components are arranged in a hierarchical manner from the dorsal horn and trigeminal nucleus to the prefrontal cortex, the latter representing the highest level of nociceptive response. ${ }^{44}$

\section{ACKNOWLEDGMENT}

The author is grateful to Professor John A. Kiernan, Dept. of Anatomy, University of Western Ontario, for his helpful advice in the preparation of the manuscript.

\section{REFERENCES}

1. Melzack R, Wall PD. Pain mechanisms: a new theory. Science 1965; 150: 971-979.

2. Talbot JD, Marrett S, Evans AC, et al. Multiple representation of pain in human cerebral cortex. Science 1991; 251: 1355-1358.

3. Penfield W, Boldrey E. Somatic motor and sensory representation in the cerebral cortex of man as studied by electrical stimulation. Brain 1937; 60: 389-443.

4. Derbyshire SWG, Jones AKP, Gyulai F, et al. Pain processing during three levels of noxious stimulation produces differential patterns of central activity. Pain 1997; 73: 431- 445

5. Leijon G, Boivie J, Johansson I. Central post-stroke pain neurological symptoms and pain characteristics. Pain 1989; 36: 13-25.

6. Vestergaard K, Nielsen J, Andersen G, et al. Sensory abnormalities in consecutive, unselected patients with central post-stroke pain. Pain 1995; 61: 177-186.

7. Davis KD, Kiss ZHT, Tasker RR, Dostrovsky JO. Thalamic stimulation-evoked sensations in chronic pain patients and in nonpain (movement disorder) patients. J Neurophysiol 1996; 75: 1026-1037

8. Bowsher D. Termination of the central pain pathway in man: the conscious appreciation of pain. Brain 1957; 80: 606-622.

9. Bentivoglio M, Kultas-Ilinksy K, Ilinsky I. Limbic thalamus: structure, intrinsic organization, and connections. In: Vogt BA, Gabriel M, eds. Neurobiology of Cingulate Cortex and Limbic Thalamus: A Comprehensive Handbook. Boston: Birkhäuser, 1993: 71-122.

10. Dong WK, Ryu H, Wagman IH. Nociceptive responses of neurons in medial thalamus and their relationship to spinothalamic pathways. J Neurophysiol 1978; 41: 1592-1613.

11. Albe-Fessard D, Berkley KJ, Kruger L, Ralston III HJ, Willis Jr WD. Diencephalic mechanisms of pain sensation. Brain Res Rev 1985; 9: 217-296.

12. Derbyshire SWG, Jones AKP, Devani P, et al. Cerebral responses to pain in patients with atypical facial pain measured by positron emission tomography. J Neurol Neurosurg Psychiatry 1994; 57: 1166-1172.

13. Smith WK. The functional significance of the rostral cingular cortex as revealed by its responses to electrical excitation. J Neurophysiol 1945; 8: 241-255.

14. Ward Jr AA. The cingular gyrus: area 24. J Neurophysiol 1948; 11: $13-23$.

15. Foltz EL, White Jr LE. Pain "relief" by frontal cingulumotomy. J Neurosurg 1962; 19: 89-100.

16. Meyer A, Beck E, McLardy T. Prefrontal leucotomy: a neuroanatomical report. Brain 1947; 70: 18-49.

17. Mark V, Ervin FR Yakovlev PI. Stereotactic thalmotomy. The verification of anatomical lesion sites in the human thalamus. Arch Neurol 1963; 8: 78-88.
18. Vogt BA, Rosene DL, Pandya DN. Thalamic and cortical afferents differentiate anterior from posterior cingulate cortex in the monkey. Science 1979; 204: 205-207.

19. Jones AKP, Brown WD, Friston KJ, Qi LY, Frackowiak RSJ. Cortical and subcortical localization of response to pain in man using positron emission tomography. Proc Royal Soc Lond B 1991a; 244: 39-44.

20. Jones AKP, Qi LY, Fujirawa T, et al. In vivo distribution of opioid receptors in man in relation to the cortical projections of the medial and lateral pain systems measured with positron emission tomography. Neurosci Lett 1991b; 126: 25-28.

21. Rosen SD, Paulesu E, Frith CD, et al. Central nervous pathways mediating angina pectoria. Lancet 1994; 344: 147-150.

22. Silverman DHS, Munakata JA, Ennes H, et al. Regional cerebral activity in normal and pathological perception of visceral pain. Gastroenterology 1997; 112: 64-72.

23. Aziz Q, Andersson JLR, Valind S, et al. Identification of human brain loci processing esophageal sensation using positron emission tomography. Gastroenterology 1997; 113: 50-59.

24. Hsieh J-C, Hannerz J, Ingvar M. Right-lateralised central processing for pain of nitroglycerin-induced cluster headache. Pain 1996; 67: 59-68.

25. Casey KL, Minoshima S, Berger KL, et al. Positron emission tomographic analysis of cerebral structures activated specifically by repetitive noxious heat stimuli. J Neurophysiol 1994; 71: 802-807.

26. Coghill RC, Talbot JD, Evans AC, et al. Distributed processing of pain and vibration by the human brain. J Neurosci 1994; 14 : 4095-4108.

27. Craig AD, Reiman EM, Evans A, Bushnell MC. Functional imaging of an illusion of pain. Nature 1996; 384: 258-260.

28. Vogt BA, Derbyshire S, Jones AKP. Pain processing in four regions of human cingulate cortex localized with co-registered PET and MR imaging. Europ J Neurosci 1996; 8: 1461-1473.

29. Hsieh J-C, Belfrage M, Stone-Elander S, Hansson P, Ingvar M. Central representation of chronic ongoing neuropathic pain studied by positron emission tomography. Pain 1995a; 63: 225236.

30. Hsieh J-C, Ståhle-Bäckdahl M, Hägermark Ö, et al. Traumatic nociceptive pain activates the hypothalamus and the periaqueductal gray: a positron emission tomography study. Pain 1995b; 64: 303-314.

31. Weiller C, May A, Limmroth V, et al. Brain stem activation in spontaneous human migraine attacks. Nature Med 1995; 1: 658660.

32. Peyron R, García-Larrea L, Grégoire MC, et al. Allodynia after lateral-medullary (Wallenberg) infarct: a PET study. Brain 1998; 121: 345-356.

33. Derbyshire SWG, Jones AKP. Cerebral responses to a continual tonic pain stimulus measured using positron emission tomography. Pain 1998; 76: 127-135.

34. Apkarian AV. Functional imaging of pain: new insights regarding the role of the cerebral cortex in human pain perception. Semin Neurosci. 1995; 7: 279-293.

35. Davis KD, Wood ML, Crawley AP, Mikulis DJ. fMRI of human somatosensory and cingulate cortex during painful electrical nerve stimulation. Neuroreport 1995; 7: 321-325.

36. Berman HH, Kim KHS, Talati A, Hirsch J. Representation of nociceptive stimuli in primary sensory cortex. Neuroreport 1998; 9: 4179-4187.

37. Davis KD, Taylor SJ, Crawley AP, Wood ML, Mikulis DJ. Functional MRI of pain-and attention-related activations in the human cingulate cortex. J Neurophysiol 1997; 77: 3370-3380.

38. Davis KD, Kwan CL, Crawley AP, Mikulis DJ. Event-related fMRI of pain: entering a new era in imaging pain. Neuroreport 1998a; 9: 3019-3023.

39. Davis KD, Kwan CL, Crawley AP, Mikulis DJ. Functional MRI study of thalamic and cortical activations evoked by cutaneous heat, cold, and tactile stimuli. J Neurophysiol 1998b; 80: 15331546.

40. Disbrow E, Buonocore M, Antognini J, Carstens E, Rowley HA. Somatosensory cortex: a comparison of the response to noxious 
thermal, mechanical, and electrical stimuli using functional magnetic resonance imaging. Human Brain Mapping 1998; 6: 150-159.

41. Oshiro Y, Fuijita N, Tanaka H, et al. Functional mapping of painrelated activation with echo-planar MRI: significance of the SIIinsular region. Neuroreport 1998; 9: 2285-2289.

42. Porro CA, Cettolo V, Francescato MP, Baraldi P. Temporal and intensity coding of pain in human cortex. J Neurophysiol 1998; 80: 3312-3320.

43. Shulman GL, Fiez JA, Corbetta M, et al. Common blood flow changes across visual tasks: II. Deceases in cerebral cortex. J Cog Neurosci 1997; 9: 648-663.

44. Jackson JH. On the comparative study of diseases of the nervous system. Br Med J 1889; 2: 355-362.

45. Petrides M, Alivisatos B, Evans AC, Meyer E. Dissociation of human mid-dorsolateral from posterior dorsolateral frontal cortex in memory processing. Proc Natl Acad Sci USA, Neurobiology 1993; 90: 873-877.

46. Damasio AR. The somatic marker hypothesis and the possible functions of the prefrontal cortex. Phil Trans R Soc Lond B 1996; 351: 1413-1420.

47. Rainer G, Asaad WF, Miller EK. Selective representation of relevant information by neurons in the primate prefrontal cortex. Nature 1998; 393:577-579.

48. Caterina MJ, Schumacher MA, Tominaga M, et al. The capsaicin receptor: a heat-activated ion channel in the pain pathway. Nature 1997; 389: 816-824.

49. Willis Jr WD. Nociceptive pathways: anatomy and physiology of nociceptive ascending pathways. Phil Trans R Soc Lond B 1985; 308: 253-268.

50. Cao YQ, Mantyh PW, Carlson EJ, et al. Primary afferent tachykinins are required to experience moderate to intense pain. Nature 1998; 392: 390-394.

51. Haley JE, Sullivan AF, Dickenson AH. Evidence for spinal Nmethyl-D-aspartate receptor involvement in prolonged chemical nociception in the rat. Brain Res 1990; 518: 218-226.

52. De Felipe C, Herrero JF, O'Brien JA, et al. Altered nociception, analgesia and aggression in mice lacking the receptor for substance P. Nature 1998; 392: 394-397.

53. Iversen L. Substance P equals pain substance? Nature 1998; 392 : 334-335.

54. Coulter JD, Jones EG. Differential distribution of corticospinal projections from individual cytoarchitectonic fields in the monkey. Brain Res 1977; 129: 335-340.

55. Cheema SS, Rustioni A, Whitsel BL. Light and electron microscopic evidence for a direct corticospinal projection to superficial laminae of the dorsal horn in cats and monkeys. J Comp Neurol 1984; 225: 276-290.

56. Liang F, Moret V, Wiesendanger M, Rouiller EM. Corticomotoneuronal connections in the rat: evidence from double-labeling of motoneurons and corticospinal axon arborizations. J Comp Neurol 1991; 311: 356-366.

57. Parent A. Carpenter's Human Neuroanatomy. 9th Edition. Baltimore: Williams \& Wilkins 1996.

58. Marek P, Mogil JS, Sternberg WF, Panocka I, Liebeskind JC. Nmethyl-D-aspartic acid (NMDA) receptor antagonist MK-801 blocks non-opioid stress-induced analgesia. II. Comparison across three swim-stress paradigms in selectively bred mice. Brain Res 1992; 578: 197-203.

59. Budai D, Fields HL. Endogenous opioid peptides acting at $\mu$ opioid receptors in the dorsal horn contribute to midbrain modulation of spinal nociceptive neurons. J Neurophysiol 1998; 79: 677-687.

60. Hardy SGP, Leichnetz GR. Cortical projections to the periaqueductal grey in the monkey: a retrograde and orthograde horseradish peroxidase study. Neurosci Lett 1981; 22: 97-101.

61. Gray TS, Magnuson DJ. Peptide immunoreactive neurons in the amygdala and the bed nucleus of the stria derminalis project to the midbrain central gray in the rat. Peptides 1992; 13: 451-460.

62. Markenson JA. Mechanisms of chronic pain. Am J Med 1996;101: (suppl 1A): 6S-18S.
63. Kiernan JA. Barr's Human Nervous System. An Anatomical Viewpoint. 7th edition. Philadelphia: Lippincott, Williams and Wilkins, 1998.

64. Iggo A, Steedman WM, Fleetwood-Walker S. Spinal processing: anatomy and physiology of spinal nociceptive mechanisms. Phil Trans R Soc Lond B 1985; 308: 235-252.

65. Proudfit HK. Pharmacologic evidence for the modulation of nociception by noradrenergic neurons. Prog Brain Res 1988; 77 : 357-370.

66. Hitoto T, Tsuruoka M, Hiruma Y, Matsui Y. Aס afferent fibre stimulation activates descending noradrenergic system from the locus coeruleus. Neurochem Res 1998; 23: 1461-1465.

67. Stanton-Hicks M, Salamon J. Stimulation of the central and peripheral nervous system for the control of pain. J Clin Neurophysiol 1997; 14: 46-62.

68. Decker MW, Bannon AW, Buckley MJ, et al. Antinociceptive effects of the novel neuronal nicotinic acetylcholine receptor agonist, ABT-594, in mice. Eur J Pharm 1998; 346: 23-33.

69. Tyler BM, Cusack B, Douglas CL, Souder T, Richelson E. Evidence for additional neurotensin subtypes: neurotensin analogs that distinguish between neurotensin-mediated hypothermia and antinociception. Brain Res 1998; 792: 246-252.

70. Iadarola MJ, Berman KF, Zeffiro TA, et al. Neural activation during acute capsaicin-evoked pain and allodynia assessed with PET. Brain 1998; 121: 931-947.

71. May A, Kaube H, Büchel C, et al. Experimental cranial pain elicited by capsaicin: a PET study. Pain 1998; 74: 61-66.

72. Giesler Jr GJ, Katter JT, Dado RJ. Direct spinal pathways to the limbic system for non-nociceptive information. Trends Neurosci 1994; 17: 244-250.

73. Jones EG, Pons TP. Thalamic and brainstem contributions to large-scale plasticity of primate somatosensory cortex. Science 1998; 282: 1121-1125.

74. Boivie J. An anatomical reinvestigation of the termination of the spinothalamic tract in the monkey. J Comp Neurol 1979; 186: 343-370.

75. Roland P. Cortical representation of pain. Trends Neurosci 1992; 15: $3-5$

76. Melzack R, Casey KL. Sensory, motivational and central control determinants of pain: a new conceptual model. In: Kenshalo DR ed. The Skin Senses. Springfield: Ill: Charles C Thomas, 1968, 423-443.

77. Vogt BA, Finch DM, Olson CR. Functional heterogeneity in cingulate cortex: the anterior executive and posterior evaluative regions. Cerebral Cortex 1992; 2: 435-443.

78. Bushnell MC, Duncan GH. Sensory and affective aspects of pain perception: is medial thalamus restricted to emotional issues? Exp Brain Res 1989; 78: 415-418.

79. Casey KL. Unit analysis of nociceptive mechanisms in the thalamus of the awake squirrel monkey. J Neurophysiol 1966; 29: 727-750

80. Lenz FA, Kwan HC, Dostrovsky JO, Tasker RR. Characteristics of the bursting pattern of action potentials that occurs in the thalamus of patients with central pain. Brain Res 1989; 496: 357-360.

81. Gorecki J, Hirayama T, Dostrovsky JO, Tasker RR, Lenz FA. Thalamic stimulation and recording in patients with deafferentation and central pain. Stereotact Funct Neurosurg 1989; 52: 219-226.

82. Hirayama T, Dostrovsky JO, Gorecki J, Tasker RR, Lenz FA. Recordings of abnormal activity in patients with deafferentation and central pain. Stereotact Funct Neurosurg 1989; 52: 120-126.

83. Rinaldi PC, Young RF, Albe-Fessard D, Chodakiewitz J. Spontaneous neuronal hyperactivity in the medial and intralaminar thalamic nuclei of patients with deafferentation pain. J Neurosurg 1991; 74: 415-421.

84. Lenz FA, Seike M, Lin YC, et al. Neurons in the area of human thalamic nucleus ventralis caudalis respond to painful heat stimuli. Brain Res 1993; 623: 235-240.

85. Lenz FA, Gracely RH, Rowland LH, Dougherty PM. A population of cells in the human thalamic principal sensory nucleus respond to painful mechanical stimuli. Neurosci Lett 1994; 180: 46-50. 
86. Lenz FA, Dougherty PM. Neurons in the human thalamic somatosensory nucleus (ventralis caudalis) respond to inocuous cool and mechanical stimuli. J Neurophysiol 1998; 79: 22272230.

87. Ghosh S, Turman AB, Vickery RM, Rowe MJ. Responses of cat ventroposterolateral thalamic neurons to vibrotactile stimulation of forelimb footpads. Exp Brain Res 1992; 92: 286298.

88. Brodmann K. Vergleichende Localization lehre der Grosshirnrinde in hiren Prinzipien dargestellt auf Grund des Zellenbaues. Leipzig: J. B. Barth, 1909.

89. Vogt BA, Nimchinsky EA, Vogt LJ, Hof PR. Human cingulate cortex: surface features, flat maps, and cytoarchitecture. J Comp Neurol 1995; 359: 490-506.

90. Vogt BA, Pandya DN. Cingulate cortex of the Rhesus monkey: II. Cortical afferents. J Comp Neurol 1987; 262: 271-289.

91. Vogt BA, Pandya DN, Rosene DL. Cingulate cortex of the Rhesus monkey: I. Cytoarchitecture and thalamic afferents. J Comp Neurol 1987; 262: 256-270.

92. Baleydier C, Mauguiere F. The duality of the cingulate gyrus in monkey. Neuroanatomical study and functional hypothesis. Brain 1980; 103: 525-554.

93. Valenstein E, Bowers D, Verfaellie M, et al. Retrosplenial amnesia. Brain 1987; 110: 1631-1646.

94. Sikes RW, Vogt B, Swadlow HA. Neuronal responses in rabbit cingulate cortex linked to quick-phase eye movements during nystagmus. J Neurophysiol 1988; 59: 922-936.

95. Devinsky O, Morrell MJ, Vogt BA. Contributions of anterior cingulate cortex to behaviour. Brain 1995; 118: 279-306.

96. Rainville P, Duncan GH, Price DD, Carrier B, Bushnell MC. Pain affect encoded in human anterior cingulate but not somatosensory cortex. Science 1997; 277: 968-971.

97. Cavada C, Goldman-Rakic P. Posterior parietal cortex in Rhesus monkey: I. Parcellation of areas based on distinctive limbic and sensory corticocortical connections. J Comp Neurol 1989; 287: 393-421.

98. Vaccarino AL, Melzack R. Temporal processes of formalin pain: differential role of the cingulum bundle, fornix pathway and medial bulboreticular formation. Pain 1992;49:257-271.

99. Sikes RW, Vogt BA. Nociceptive neurons in area 24 of rabbit cingulate cortex. J Neurophysiol 1992; 68: 1720-1732.

100. Hirai T, Jones EG. A new parcellation of the human thalamus on the basis of histochemical staining. Brain Res Rev 1989a; 14: 134.

101. Hirai T, Jones EG. Distribution of tachykinin- and enkephalinimmunoreactive fibres in the human thalamus. Brain Res Rev 1989b; 14: 35-52

102. Pillay PK, Hassenbusch SJ. Bilateral MRI-guided stereotactic cingulotomy for intractable pain. Stereotact Funct Neurosurg 1992; 59: 33-38.

103. Jones EG, Powell TPS. An anatomical study of converging sensory pathways within the cerebral cortex of the monkey. Brain 1970; 93: 793-820.

104. Amaral DG. Memory: anatomical organization of candidate brain regions. In: Plum F. ed. Handbook of Physiology; The Nervous System. Vol V. Higher Functions of the Brain, Part 1. Bethesda: Amer Physiol Soc, 1987: 211-294.

105. Friedman DP, Murray EA, O'Neill JB, Mishkin M. Cortical connections of the somatosensory fields of the lateral sulcus of macaques: evidence for a corticolimbic pathway for touch. $\mathbf{J}$ Comp Neurol 1986: 252; 323-347.

106. Schneider RJ, Friedman DP, Mishkin M. A modality-specific somatosensory area within the insula of the Rhesus monkey. Brain Res 1993; 621: 116-120.

107. Mesulam M.-M, Mufson EJ. The insula of Reil in man and monkey. Architectonics, connectivity, and function. In: Peters A, Jones EG, eds. Cerebral Cortex. Vol 4. Association and Auditory Cortices. New York: Plenum Press, 1985: 179-226.

108. Hoffman BL, Rasmussen T. Stimulation studies of insular cortex of Macaca mulatta. J Neurophysiol 1953: 16; 343-351.

109. Penfield W, and Faulk Jr ME. The insula. Further observations on its function. Brain 1955: 78; 445-470.
110. Mufson EJ, Mesulam M. -M. Insula of the old world monkey. II: Afferent cortical input and comments on the claustrum. J Comp Neurol 1982: 212; 23-37.

111. Hoover JE, Strick PL. Multiple output channels in the basal ganglia. Science 1993; 259: 819-821.

112. Deniau JM, Menetrey A, Thierry AM. Indirect nucleus accumbens input to the prefrontal cortex via the substantia nigra pars reticulata: a combined anatomical and electrophysiological study in the rat. Neuroscience 1994; 61: 533-545.

113. Brown P, Marsden CD. What do basal ganglia do? Lancet 1998; 351: 1801-1804

114. Cahill L, Haier RJ, Fallon J, et al. Amygdala activity at encoding correlated with long-term, free recall of emotional information. Proc Natl Acad Sci USA 1996; 93: 8016-8021.

115. Morris JS, Öhman A, Dolan RJ. Conscious and unconscious emotional learning in the human amygdala. Nature 1998: 393; 467-470.

116. Galvez R, Mesches MH, McGaugh JL. Norepinepherine release in the amygdala in response to footshock stimulation. Neurobiol Learning Memory 1996; 66: 253-257.

117. Amaral DG, Price JL, Pitkänen A, Carmichael ST. Anatomical organization of the primate amygdaloid complex. In: Aggleton JP, ed. The Amygdala: Neurobiological Aspects of Emotion, Memory, and Mental Dysfunction. New York: Wiley-Liss Inc., 1992: 1-66.

118. Amaral DG, Price JL. Amygdalo-cortical projections in the monkey (Macaca fascicularis). J Comp Neurol 1984; 230: 465496.

119. Van Hoesen GW, Morecraft RJ, Vogt BA. Connections of the monkey cingulate cortex. In: Vogt BA, Gabriel M, eds. Neurobiology of Cingulate Cortex and Limbic Thalamus: A Comprehensive Handbook. Boston: Birkhäuser, 1993: 249-284.

120. Price JL, Amaral DG. An autoradiographic study of the projections of the central nucleus of the monkey amygdala. J Neurosci 1981; 1: 1242-1259.

121. Rolls ET. Neurophysiology and functions of the primate amygdala. In: Aggleton JP, ed. The Amygdala: Neurobiological Aspects of Emotion, Memory, and Mental Dysfunction. New York: Wiley-Liss Inc., 1992: 143-165.

122. Chapman WP, Schroeder HR, Geyer G, et al. Physiological evidence concerning importance of the amygdaloid nuclear region in the integration of circulatory function and emotion in man. Science 1954; 120: 949-950.

123. Weiskrantz L. Behavioural changes associated with ablation of the amygdaloid complex in monkeys. J Comp Physiol Psychol 1956; 49: 381-391.

124. Ono T, Nishijo H. Neurophysiological basis of the Klüver-Bucy syndrome: responses of monkey amygdaloid neurons to biologically significant objects. In: Aggleton JP, ed. The Amygdala: Neurobiological Aspects of Emotion, Memory, and Mental Dysfunction. New York: Willey-Liss Inc., 1992: 167190.

125. Graeff FG, Silveira MCL, Nogueira RL, Audi EA, Oliveira RMW. Role of the amygdala and periaquedectal gray in anxiety and panic. Behav Brain Res 1993; 58: 123-131.

126. Nashold Jr BS, Wilson WP, Slaughter G. The midbrain and pain. Adv Neurol 1974; 4: 191-196.

127. Bolles RC, Fanselow MS. A perceptual-defensive-recuperative model of fear and pain. Behav Brain Sci 1980; 3: 291-323.

128. Graeff FG. Brain defense systems and anxiety. In: Burrows GD, Roth M, Noyes Jr R, eds. Handbook of Anxiety. Vol. 3: The Neurobiology of Anxiety. New York: Elsevier Science Publishers, 1990: 307-354..

129. Fanselow MS. The midbrain periaqueductal gray as a coordinator of action in response to fear and anxiety. In: Depaulis A, Bandler R, eds. The Midbrain Periaqueductal Gray Matter. New York: Plenum Press, 1991: 151-173.

130. Deakin JWF, Graeff FG. 5-HT and mechanisms of defence. J Psychopharmacol 1991; 5: 305-315.

131. Davis $\mathrm{M}$. The role of the amygdala in conditioned fear. In: Aggleton JP, ed. The Amygdala: Neurobiological Aspects of Emotion, Memory, and Mental Dysfunction. New York: WileyLiss Inc., 1992: 255-305. 
132. McGaugh JL, Intoini-Collison IB, Cahill L, Kim M, Liang KC. Involvement of the amygdala in neuromodulatory influences on memory storage. In: Aggleton JP, ed. The Amygdala: Neurobiological Aspects of Emotion, Memory, and Mental Dysfunction. New York: Wiley-Liss Inc., 1992: 431-451.

133. McGaugh JL, Introini-Collison IB, Cahill LF, et al. Neuromodulatory systems and memory storage: role of the amygdala. Behav Brain Res 1993; 58: 81-90.

134. LeDoux JE. Emotional memory systems in the brain. Behav Brain Res 1993; 58: 69-79.

135. Adolphs R, Tranel D, Damasio H, Damasio A. Impaired recognition of emotion in facial expressions following bilateral damage to the human amygdala. Nature 1994; 372: 669-672.

136. Cahill L, Babinsky R, Markowitsch HJ, McGaugh JL. The amygdala and emotional memory. Nature 1995; 377: 295-296.

137. Scott SK, Young AW, Calder AJ, et al. Impaired auditory recognition of fear and anger following bilateral amygdala lesions. Nature 1997; 385: 254-257.

138. Walter WG. The convergence and interaction of visual, auditory and tactile responses in human nonspecific cortex. Ann N Y Acad Sci 1964; 112: 320-361.

139. Giguere M, Goldman-Rakic PS. Mediodorsal nucleus: areal, laminar, and tangential distribution of afferents and efferents in the frontal lobe of Rhesus monkeys. J Comp Neurol 1988; 277: 195-213.

140. Fuster JM. The Prefrontal Cortex. Anatomy, Physiology and Neuropsychology of the Frontal Lobe. Philadelphia: LippincottRaven, 1997.

141. Pandya DN, Dye P, Butters N. Efferent cortico-cortical projections of the prefrontal cortex in the Rhesus monkey. Brain Res 1971; 31: 35-46.

142. Barbas H, Pandya DN. Architecture and intrinsic connections of the prefrontal cortex in the Rhesus monkey. J Comp Neurol 1989; 286: 353-375.

143. Pandya DN, Van Hoesen GW, Mesulam M.-M. Efferent connections of the cingulate gyrus in the Rhesus monkey. Exp Brain Res 1981; 42: 319-330.

144. Pandya DN, Kuypers HGJM. Cortico-cortical connections in the Rhesus monkey. Brain Res 1969; 13: 13-36.

145. Goldman-Rakic PS, Porrino LJ. The primate mediodorsal (MD) nucleus and its projection to the frontal lobe. J Comp Neurol 1985; 242: 535-560.

146. Pardo JV, Fox PT, Raichle ME. Localization of a human system for sustained attention by positron emission tomography. Nature 1991; 349: 61-64.

147. Courtney SM, Petit L, Maisog JM, Ungerleider LG, Haxby JV. An area specialized for spatial working memory in human frontal cortex. Science 1998; 279: 1347-1351.

148. Goldman-Rakic PS, Selemon LD, Schwartz ML. Dual pathways connecting the dorsolateral prefrontal cortex with the hippocampal formation and parahippocampal cortex in the Rhesus monkey. Neuroscience 1984; 12: 719-743.

149. Bechara A, Damasio H, Tranel D, Damasio AR. Deciding advantageously before knowing the advantageous strategy. Science 1997; 275: 1293-1295.

150. Vogel G. Scientists probe feelings behind decision-making. Science 1997; 275: 1269.

151. Koechlin E, Basso G, Pietrini P, Panzer S, Grafman J. The role of the anterior prefrontal cortex in human cognition. Nature 1999; 399: 148-151.

152. Scarff JE. Unilateral prefrontal lobotomy for the relief of intractable pain and termination of narcotic addiction. Surg Gynec Obstet 1949; 89: 385-392.

153. Tucker WI. Results of lobotomy. J Neuropsychiat 1961; 2: 153-157.

154. Meyer M.A study of efferent connexions of the frontal lobe in the human brain after leucotomy. Brain 1949; 72: 265-296.

155. Glees P, Cole J, Whitty CWM, Cairns H. The effects of lesions in the cingular gyrus and adjacent areas in monkeys. J Neurol Neurosurg Psychiatry 1950; 13: 178-190.

156. Freemen W, Watts JW. Psychosurgery in the Treatment of Mental Disorders and Intractable Pain. Springfield Illinois: Charles C Thomas, 1950.
157. Picard N, Strick PL. Motor areas of the medial wall: a review of their location and functional activation. Cerebral Cortex 1996; 6: 342-353.

158. Goldman-Rakic PS. Motor control function of the prefrontal cortex. In: Bock G, O’Connor M, Marsh J, eds. Motor Areas of the Cerebral Cortex. Ciba Foundation Symposium 132, Chichester: John Wiley and Sons, 1987: 187-200.

159. $\mathrm{Lu} \mathrm{M-T,} \mathrm{Preston} \mathrm{JB,} \mathrm{Strick} \mathrm{PL.} \mathrm{Interconnections} \mathrm{between} \mathrm{the}$ prefrontal cortex and the premotor areas in the frontal lobe. J Comp Neurol 1994; 341: 375-392.

160. Braak H. A primitive gigantopyramidal field buried in the depth of the cingulate sulcus of the human brain. Brain Res 1976; 109: 219-233.

161. Selemon LD, Goldman-Rakic PS. Common cortical and subcortical targets of the dorsolateral prefrontal and posterior parietal cortices in the Rhesus monkey: evidence for a distributed neural network subserving spatially guided behaviour. J Neurosci 1988; 8: 4049-4068.

162. Morecraft RJ, Van Hoesen GW. Cingulate input to the primary and supplementary motor cortices in the Rhesus monkey: evidence for somatotopy in areas $24 \mathrm{c}$ and $23 \mathrm{c}$. J Comp Neurol 1992; 322: 471-489.

163. Dum RP, Strick PL. Cingulate motor areas. In: Vogt BA, Gabriel $M$, eds. Neurobiology of Cingulate Cortex and Limbic Thalamus: A Comprehensive Handbook. Boston: Birkhäuser, 1993: 415-441.

164. Neafsey EJ, Terreberry RR, Hurley KM, Ruit KG, Frysztak RJ. Anterior cingulate cortex in rodents: connections, visceral control functions, and implications for emotion. In: Vogt BA, Gabriel M, eds. Neurobiology of Cingulate Cortex and Limbic Thalamus: A Comprehensive Handbook. Boston: Birkhäuser, 1993: 206-223.

165. Vogt BA. Structural organization of cingulate cortex: areas, neurons, and somatodendritic transmitter receptors. In: Vogt BA, Gabriel M, eds. Neurobiology of Cingulate Cortex and Limbic Thalamus: A Comprehensive Handbook. Boston: Birkhäuser, 1993: 19-70.

166. Avendaño C, Price JL, Amaral DG. Evidence for an amygdaloid projection to premotor cortex but not to motor cortex in the monkey. Brain Res 1983; 264: 111-117.

167. Coderre TJ, Katz J, Vaccarino AL, Melzack R. Contribution of central neuroplasticity to pathological pain: review of clinical and experimental evidence. Pain 1993; 52: 259-285.

168. Ploghaus A, Tracey I, Gati JS, et al. Dissociating pain from its anticipation in the human brain. Science 1999; 284: 1979-1981.

169. MacLean PD. The limbic system ("visceral brain") and emotional behaviour. Arch Neurol Psychiatry 1955; 73: 130-134.

170. Freeman Jr JH, Cuppernell C, Flannery K, Gabriel M. Limbic thalamic, cingulate cortical and hippocampal neuronal correlates of discriminative approach learning in rabbits. Behav Brain Res 1996; 80: 123-136. 